\title{
A new flexible multicomponent model for the study of aerosol dynamics in the marine boundary layer
}

Karl, Matthias

2011

Karl , M , Gross , A , Pirjola , L \& Leck , C 2011, ' A new flexible multicomponent model for the study of aerosol dynamics in the marine boundary layer ' , Tellus. Series B: Chemical and Physical Meteorology , vol. 63 , pp. 1001-1025 . https://doi.org/10.1111/j.1600-0889.2011.00562.x

http://hdl.handle.net/10138/162027

https://doi.org/10.1111/j.1600-0889.2011.00562.x

cc_by_nc

publishedVersion

Downloaded from Helda, University of Helsinki institutional repository.

This is an electronic reprint of the original article.

This reprint may differ from the original in pagination and typographic detail.

Please cite the original version. 


\title{
A new flexible multicomponent model for the study of aerosol dynamics in the marine boundary layer
}

\author{
By MATTHIAS KARL ${ }^{1 *}$, ALLAN GROSS ${ }^{2}$, LIISA PIRJOLA ${ }^{3,4}$ and CAROLINE LECK ${ }^{5}$, \\ ${ }^{1}$ Department for Urban Environment and Industry, Norwegian Institute for Air Research, P.O. Box 100, NO-2027 \\ Kjeller, Norway; ${ }^{2}$ Department of Atmospheric Environment, National Environment Research Institute, Aarhus \\ University, Frederiksborgvej 399, DK-4000 Roskilde, Denmark; ${ }^{3}$ Department of Physical Sciences, University of \\ Helsinki, P.O. Box 64, FI-00014 Helsinki, Finland; ${ }^{4}$ Department of Technology, Metropolia University of Applied \\ Sciences, P.O. Box 4000, FI-00180 Helsinki, Finland; ${ }^{5}$ Department of Meteorology, Stockholm University, \\ Svante Arrhenius väg 16C, S-10691 Stockholm, Sweden
}

(Manuscript received 14 September 2010; in final form 31 May 2011)

\begin{abstract}
A new sectional aerosol dynamics model, MAFOR, was developed with the focus to study nucleation in the marine boundary layer. Novel aspects of the model are (1) flexibility in the treatment of gas phase chemistry, (2) treatment of liquid phase chemistry, which can be extended according to needs and (3) simultaneous calculation of number and mass concentration distributions of a multicomponent aerosol as functions of time. Comparison with well-documented aerosol models (MONO32 and AEROFOR), a comprehensive data set on gas phase compounds, aerosol size distribution and chemical composition obtained during the AOE-96 (Arctic Ocean Expedition, 1996) was used to evaluate the model. Dimethyl sulphide decay during advection of an air parcel over the Arctic pack ice was well captured by the applied models and predicted concentrations of gaseous sulphuric acid and methane sulphonic acid range up to $1.0 \times 10^{6} \mathrm{~cm}^{-3}$ and $1.8 \times 10^{6} \mathrm{~cm}^{-3}$, respectively. Different nucleation schemes were implemented in MAFOR which allow the simulation of new particle formation. Modelled nucleation rates from sulphuric acid nucleation via cluster activation were up to $0.21 \mathrm{~cm}^{-3} \mathrm{~s}^{-1}$ while those from ion-mediated nucleation were below $10^{-2} \mathrm{~cm}^{-3} \mathrm{~s}^{-1}$. Classical homogeneous binary and ternary nucleation theories failed to predict nucleation over the central Arctic Ocean in summer.
\end{abstract}

\section{Introduction}

The aerosol indirect radiative effect is poorly constrained in the existing climate models and this represents the single greatest uncertainty in assessing the climate change (Penner et al., 2001; IPCC, 2007). For a given cloud water content, cloud reflectivity increases with the state of division of the cloud elements (Twomey, 1974). The microphysical properties of clouds warmer than $0{ }^{\circ} \mathrm{C}$ depend strongly on the concentration of airborne aerosol particles having a water-soluble component beyond a critical mass, known as cloud condensation nuclei (CCN).

Nucleation events, that is, the formation of ultrafine particles (diameter between $3 \mathrm{~nm}$ and $25 \mathrm{~nm}$ ) and their subsequent growth to larger sizes, have been observed in the marine boundary layer (BL) (Hoppel et al., 1994; Weber et al., 1998; Clarke et al., 1998). Over remote oceans particles with sizes less than $20 \mathrm{~nm}$

\footnotetext{
* Corresponding author.

e-mail: mka@nilu.no

DOI: $10.1111 / \mathrm{j} .1600-0889.2011 .00562 . \mathrm{x}$
}

diameter typically do not occur frequently (Heintzenberg et al., 2004). On the other hand, new particle formation events are relatively common in coastal areas (O'Dowd et al., 1998, 1999; Modini et al., 2009), in Antarctic areas (O'Dowd et al., 1997; Virkkula et al., 2007; Asmi et al., 2009), and in Arctic areas (Shaw, 1989; Heintzenberg and Leck, 1994; Ferek et al., 1995; Wiedensohler et al., 1996; Pirjola et al., 1998; Leck and Bigg, 1999; Leck and Bigg, 2010; Ström et al., 2009). The available number of nuclei for the initial cloud condensation will largely depend on the ability of the newly formed ultrafine particles to grow to size where they could act as $\mathrm{CCN}$.

One of the major difficulties in specifying the indirect effect of aerosol particles on climate arises from the very large number of potential aerosol sources in continental areas and atmospheric transformation during transport of the particles to the most remote parts of the globe. The Arctic summer atmosphere is nearly free from influences of continental or anthropogenic sources and constitutes a clean environment ideal to study aerosol processes. The Ymer- 80 expedition to the fringes of the pack ice region of the central Arctic Ocean (Lannefors 
et al., 1983) was the first major attempt to measure Arctic summer unperturbed aerosols and trace gases. Average total aerosol number concentration was rather low, typically less than hundred of particles per cubic centimetre. The properties of summertime Arctic aerosol, enhanced Aitken mode (25-80 nm diameter) particle number concentrations along with a very low accumulation mode (> 80-1000 nm diameter) were confirmed in other studies in the same area (Covert et al., 1996; Bigg et al., 1996; Bigg et al., 2001; Heintzenberg et al., 2006). Together, these results suggest that the central Arctic Ocean in summer might provide a site where there were few sources of aerosol particles and where optically thin stratiform clouds whose reflectivities would be influenced by CCN concentrations were frequent (Twomey, 1974).

A series of subsequent studies (Leck et al., 1996, 2001) of atmospheric aerosol over pack ice in the central Arctic Ocean have raised questions about the origin of aerosol particles that can act as CCN. It was suggested that the oxidation of dimethyl sulphide (DMS), which is produced by marine phytoplankton and subsequently released from the ocean into the atmosphere, is an important source of particles (Charlson et al., 1987). DMS emitted from the ocean south of the Arctic ice shield was found to be advected into the pack ice region (Leck and Persson, 1996a, 1996b) and was postulated to be linked to particle production over the central Arctic Ocean. Indeed were measurements of the CCN composition (Leck and Persson, 1996b) consistent with aerosol grown from the oxidation products of DMS released in the upper most ocean surface when zooplankton graze on phytoplankton around the life-affirming ice edges of the pack ice area. However, as fogs and low clouds were found to cause a very rapid turnover of particles entering the atmosphere over the pack ice (Nilsson and Leck, 2002) it seemed relevant to ask the question: How could the particles survive long enough to grow from nucleation sizes around $3 \mathrm{~nm}$ to $10 \mathrm{~nm}$ diameter to $\mathrm{CCN}$ size around $100 \mathrm{~nm}$ diameter in the presence of frequent fogs and low-level clouds?

Based on theoretical considerations, it has been postulated that nucleation continuously provides a reservoir of thermodynamically stable clusters (TSC) below $3 \mathrm{~nm}$ diameter size (Kulmala et al., 2000). Sulphuric acid is probably the most important nucleation agent in the air over remote oceans (Shaw, 1989; Kreidenweis et al., 1991; Ferek et al., 1995; Weber et al., 1995, 1998). Several nucleation mechanisms involving sulphuric acid have been proposed. The most common mechanisms are classical binary (Kulmala et al., 1998; Vehkamäki et al., 2002) and ternary nucleation theory. Homogeneous binary nucleation of water and sulphuric acid, $\mathrm{H}_{2} \mathrm{O}-\mathrm{H}_{2} \mathrm{SO}_{4}$, most likely occurs in the free troposphere (Raes, 1995) from where fresh particles may be mixed downwards. Wiedensohler et al. (1996) presented statistical evidence to suggest that the ultrafine and Aitken particles observed in the BL over the Arctic pack ice area probably come from higher altitudes. Subsequently, Leck and Bigg (1999) used the BL structure and the vertical distribution of particles during nucleation events to show that if the ultrafine and Aitken particles did come from above, it was from a level $<250 \mathrm{~m}$ above the surface and not from the free troposphere.

Binary nucleation of water and another important DMS oxidation product, methanesulphonic acid (MSA), was postulated to be responsible for particle formation in humid air (Hatakeyama et al., 1985). However, due to the low concentrations of MSA prevailing over the remote oceans it was concluded that binary nucleation of $\mathrm{H}_{2} \mathrm{O}-\mathrm{MSA}$ is of minor importance compared to binary $\mathrm{H}_{2} \mathrm{O}-\mathrm{H}_{2} \mathrm{SO}_{4}$ nucleation (Hoppel, 1987; Kreidenweis and Seinfeld, 1988a; Wyslouzil et al., 1991b; Van Dingenen and Raes, 1993), instead MSA is expected to mainly participate in the subsequent growth of nucleated particles by condensation (Kreidenweis and Seinfeld, 1988b). An extension of the binary nucleation theory is the ternary nucleation model (Korhonen et al., 1999; Napari et al., 2002a, 2002b) of $\mathrm{H}_{2} \mathrm{SO}_{4}-\mathrm{H}_{2} \mathrm{O}$-ammonia $\left(\mathrm{NH}_{3}\right)$. This theory gives significantly higher nucleation rates and thus predicts nucleation at typical tropospheric sulphuric acid $\left(1 \times 10^{5}\right.$ to $\left.1 \times 10^{7} \mathrm{~cm}^{-3}\right)$ and ammonia (some pptv) concentrations. Recently, the discovery of ammonium bisulphate cluster formation (Anttila et al., 2005) led to a revision of the ternary nucleation model (Merikanto et al., 2007). The nucleation rates from the new parameterization are several orders of magnitude lower than the ones predicted by Napari et al. (2002a). Significant ternary nucleation rates are found in the upper troposphere and in the lower troposphere if concentration of sulphuric acid and ammonia are high (Merikanto et al., 2007). Ion-mediated nucleation (Raes et al., 1986; Yu and Turco, 2000) is probably a common mechanism for new particle formation, since charged clusters (diameter $<2 \mathrm{~nm}$ ) produced by ionization of air through galactic cosmic rays (GCR) have been shown to be always present in the atmosphere (Hõrrak et al., 1998; Kulmala et al., 2007). Other concepts for nucleation are dimer controlled nucleation (Lushnikov and Kulmala, 1998), homogeneous nucleation of iodide constituents in coastal environments (O'Dowd et al., 2002; Pirjola et al., 2005; Pechtl et al., 2006; Saiz-Lopez et al., 2006; Vuollekoski et al., 2009), and the participation of sulphuric acid in the kinetic nucleation and activation mechanisms (Kulmala et al., 2006). Leck and Bigg (1999) proposed a mechanism of co-production of freshly nucleated particles $(<5 \mathrm{~nm})$ and particles of up to $50 \mathrm{~nm}$ sizes following evaporation of haze and fog droplets over the Arctic open leads (open water surfaces between ice floes). Leck and Bigg (1999) attributed the formation of the very small particles to the nucleation of an amino acid (L-methionine) of marine biological origin which they supposed to be released during the evaporation of haze and fog droplets.

Growth of stable clusters to detectable sizes $(>3 \mathrm{~nm}$ ) or further to CCN (Kulmala, 2003) within one or more hours can only occur either by self-coagulation, if concentration of pre-existing particles is low, or by condensable vapours (organics, inorganic acid, ammonia), if these are present in high concentration (several pptv), conditions that do not apply over the Arctic pack ice 
area. Observations of newly formed particles in the marine BL revealed a factor of about 10 times faster growth rates than can be explained by the binary and ternary nucleation mechanisms (e.g. Weber et al., 1998; O’Dowd et al., 1999). Model calculations indicate that a source rate of an additional (organic) condensable vapour of $5 \times 10^{7} \mathrm{~cm}^{-3} \mathrm{~s}^{-1}$ is required to reproduce the observations of coastal nucleation events (Pirjola et al., 2002). A faster growth means less time for scavenging and thus the probability increases that nucleated particles reach the Aitken mode and commute themselves into $\mathrm{CCN}$. High nucleation rates together with the presence of an additional condensable compound make atmospheric nucleation an important process in urban, rural and marine environments (Pirjola et al., 2004).

The first objective of this paper is to present a new sizeresolved aerosol dynamics model, MAFOR (Marine Aerosol Formation model). In a previous study of the aerosol formation in the marine BL (Karl et al., 2007) the monodisperse aerosol dynamics model MONO32 (Pirjola and Kulmala, 2000; Pirjola et al., 2003) was used. However, monodisperse models are not appropriate for the modelling of continuous (several hours) or more intense nucleation events, unless an additional mode is inserted to allocate the newly evolving $1 \mathrm{~nm}$ diameter sized particles. Hence, the sectional model MAFOR was mainly developed to overcome the limitations of MONO32 with respect to nucleation modelling.

AEROFOR (Pirjola, 1999) is a Lagrangian type sectional box model to study new particle formation and growth. With AEROFOR it is possible to follow the particle size distribution as a function of time; however all particles are composed of $\mathrm{H}_{2} \mathrm{SO}_{4}-\mathrm{H}_{2} \mathrm{O}$. Subsequently, AEROFOR2 (Pirjola and Kulmala, 2001) was developed to allow for multicomponent condensation and particles of different composition classes for soluble, weakly soluble and insoluble particles. Both AEROFOR and AEROFOR2 are coupled to a gas phase chemistry module, the modified EMEP chemistry scheme (Simpson, 1992), added on the DMS chemistry by Saltelli and Hjorth (1995). Both models have limitations with respect to the treatment of liquid phase chemistry and they do not solve mass concentration distributions as function of time. Table 1 provides an overview of selected sectional aerosol models in comparison with the newly developed model, including two more recent sectional multicomponent models, UHMA (Korhonen et al., 2004) and SALSA (Kokkola et al., 2008).

MAFOR was designed with the objective to study aerosol evolution in the marine BL. Novel aspects of the coupled gas phase/aerosol model MAFOR are (1) the full flexibility of gas phase chemistry and the degree of detail specifically in the chemistry of DMS, (2) the detailed treatment of liquid phase chemistry (gas/liquid equilibrium partitioning, dissociation equilibrium reactions, aqueous phase chemical reactions), which can be extended according to needs and (3) simultaneous solution of the time evolution of the particle number and mass concentra- tion distribution of a multicomponent aerosol using a sectional approach.

The second objective of the paper is to compare the new sectional model MAFOR with the two well-documented aerosol dynamics box models AEROFOR and MONO32. MONO32 has been found to predict reasonably well both the particle number concentrations and the particle size distribution and performs even better than sectional methods with low size resolution (Pirjola et al., 1999a; Korhonen et al., 2003). The monodisperse model MONO32 and the sectional model AEROFOR2 have earlier been tested against measurements available from the Biogenic Aerosol Formation in the Boreal Forest 3 (BIOFOR3) campaign (Pirjola et al., 2003) and produced comparable results in several sensitivity tests. In this work, the chemistry modules in MONO32 and AEROFOR were replaced by a chemistry mechanism based on RACM (Regional Atmospheric Chemistry Mechanism; Stockwell et al., 1997) and the EL CID DMS scheme (EL CID, 2003; Karl et al., 2007). The EL CID scheme contains updated mechanistic and kinetic data, has been evaluated with chamber experiments and is suitable for the simulation of DMS chemistry in clean and polluted marine air. Due to its high degree of detail, the EL CID scheme offers the necessary flexibility to study the sensitivity of DMS oxidation products to their specific production and loss pathways. For the comparison of the aerosol models in this work, model runs were carried out with the same initial configurations of MAFOR, AEROFOR and MONO32 using a marine transport scenario over the Arctic pack ice area north of $80^{\circ} \mathrm{N}$ similar to the scenario described by Kerminen and Leck (2001). Comparison of MAFOR simulation results with simulation results from MONO32, AEROFOR and measurements was used to evaluate the new aerosol model. Moreover, the nucleation probability over the central Arctic Ocean was addressed with the new model.

\section{Model description}

A 0-dimensional Lagrangian type sectional aerosol box model, MAFOR version 1.0, which includes gas phase and aqueous phase chemistry in addition to aerosol dynamics, was developed. The following processes are considered: (1) multiphase chemistry of the BL, (2) emission of gases, (3) condensation/evaporation of $\mathrm{H}_{2} \mathrm{SO}_{4}$, MSA and one organic vapour onto/from pre-existing particles, (4) Brownian coagulation of particles, (5) nucleation (different mechanisms, see below), (6) dry deposition of gases and particles and (7) wet deposition of particles. Growth of particles occurs through condensation of inorganic or organic vapours onto particles and coagulation. The water content of aerosol particles is parameterized with empirical polynomials for the mass fraction of solute as function of water activity (Tang and Munkelwitz, 1994).

The time evolution of the particle number and mass concentration distribution of a multicomponent aerosol is solved using 
Table 1. Comparison of selected zero-dimensional sectional aerosol dynamics models

\begin{tabular}{|c|c|c|c|c|c|}
\hline & $\begin{array}{c}\text { AEROFOR } \\
\text { Pirjola (1999) }\end{array}$ & $\begin{array}{c}\text { AEROFOR2 } \\
\text { Pirjola and Kulmala } \\
\text { (2001) }\end{array}$ & $\begin{array}{c}\text { UHMA } \\
\text { Korhonen et al. } \\
\text { (2004) }\end{array}$ & $\begin{array}{c}\text { SALSA } \\
\text { Kokkola et al. } \\
(2008)\end{array}$ & $\begin{array}{l}\text { MAFOR } \\
\text { This Work }\end{array}$ \\
\hline Primary objective & $\begin{array}{c}\text { Formation of } \\
\mathrm{H}_{2} \mathrm{SO}_{4} / \mathrm{H}_{2} \mathrm{O} \\
\text { particles }\end{array}$ & Boreal forest aerosol & $\begin{array}{l}\text { New particle } \\
\text { formation and } \\
\text { growth }\end{array}$ & $\begin{array}{c}\text { Aerosol climate } \\
\text { effects }\end{array}$ & $\begin{array}{l}\text { Marine aerosol } \\
\text { formation }\end{array}$ \\
\hline Gas-phase chemistry & $\begin{array}{l}\text { Modified EMEP } \\
\text { scheme } \\
\text { (Simpson, 1992) }\end{array}$ & $\begin{array}{c}\text { Modified EMEP } \\
\text { scheme (Simpson, } \\
\text { 1992) }\end{array}$ & - & - & $\begin{array}{c}\text { MECCA scheme } \\
\text { (Sander et al., } \\
\text { 2005) }\end{array}$ \\
\hline $\begin{array}{l}\text { DMS chemistry: } \\
\text { reactions/compounds }\end{array}$ & $\begin{array}{c}\text { 32/14 (Saltelli and } \\
\text { Hjorth, 1995) }\end{array}$ & $\begin{array}{c}\text { 32/14 (Saltelli and } \\
\text { Hjorth, 1995) }\end{array}$ & $-1-$ & $-1-$ & $\begin{array}{c}\text { 65/30 (Karl et al., } \\
\text { 2007) }\end{array}$ \\
\hline Liquid phase chemistry & No & No & $\begin{array}{c}\text { Thermo dynamic } \\
\text { equilibrium } \\
\text { models }\end{array}$ & $\begin{array}{c}\text { Oxidation of } \mathrm{SO}_{2} \\
\text { in clouds }\end{array}$ & $\begin{array}{c}\text { MECCA scheme } \\
\text { (Sander et al., } \\
\text { 2005) }\end{array}$ \\
\hline $\begin{array}{c}\text { Number or mass } \\
\text { concentration }\end{array}$ & Number & Number (composition) & Number and mass & $\begin{array}{l}\text { Number } \\
\text { (composition) }\end{array}$ & Number and mass \\
\hline $\begin{array}{l}\text { Size resolution, } D_{p} \text { in } \\
\mu \mathrm{m}^{\mathrm{a}}\end{array}$ & $0.001-2$ (optional) & 0.001-10 (optional) & $0.0007-2$ (optional) & $0.003-10(20)$ & $0.001-10$ (optional) \\
\hline $\begin{array}{l}\text { Typical number of } \\
\text { aerosol components }\end{array}$ & 1 & 9 & Unspecified & 6 & 7 \\
\hline $\begin{array}{l}\text { Condensing vapours } \\
\text { other than water }\end{array}$ & $\mathrm{H}_{2} \mathrm{SO}_{4}$ & $\mathrm{H}_{2} \mathrm{SO}_{4}, \mathrm{OV}$ & $\begin{array}{c}\mathrm{H}_{2} \mathrm{SO}_{4}, \mathrm{NH}_{3}, \mathrm{OV} 1, \\
\mathrm{OV} 2^{\mathrm{b}}\end{array}$ & $\mathrm{H}_{2} \mathrm{SO}_{4}, \mathrm{OV}$ & $\mathrm{H}_{2} \mathrm{SO}_{4}, \mathrm{MSA}, \mathrm{OV}$ \\
\hline Nucleation & Several options & Several options & $\begin{array}{l}\text { Several options, } \\
\text { Nano-Köhler }\end{array}$ & Several options & Several options \\
\hline $\begin{array}{l}\text { Activation/interactions } \\
\text { with fog and cloud }\end{array}$ & No & No & Yes & Yes & $\mathrm{No}^{\mathrm{c}}$ \\
\hline Particle population & Monomer & $\begin{array}{l}\text { Externally and/or } \\
\text { internally mixed }\end{array}$ & Internally mixed & $\begin{array}{c}\text { Externally and/or } \\
\text { internally mixed } \\
\text { in } 3 \text { subranges }\end{array}$ & Internally mixed \\
\hline Aerosol size distribution & Logarithmic & Logarithmic & Logarithmic & Volume ratio & Logarithmic \\
\hline $\begin{array}{l}\text { Aerosol size distribution } \\
\text { over time }\end{array}$ & Fixed sectional & Fixed sectional & $\begin{array}{l}\text { Hybrid structure; } \\
\text { moving centre; } \\
\text { retracking }\end{array}$ & $\begin{array}{l}\text { Moving centre; } \\
\text { fixed-sectional }\end{array}$ & Fixed sectional \\
\hline $\begin{array}{l}\text { Implementation into 3-D } \\
\text { models }\end{array}$ & No & No & Planned & $\begin{array}{c}\text { ECHAM5-HAM } \\
\text { (Roeckner et al., } \\
\text { 2003) }\end{array}$ & Planned \\
\hline
\end{tabular}

aThe number in parenthesis is the number of size sections, 'optional' if model user can select.

${ }^{\mathrm{b}}$ An unspecified number of water-soluble and water-insoluble organic compounds can be included.

${ }^{\mathrm{c}}$ Will be implemented in the next model version.

the fixed sectional method. The fixed sectional method is computationally efficient and is also advantageous when treating continuous nucleation, which is important for the modelling of new particle formation. A fixed sectional grid is used where the number of size sections can be selected by the user. In this work 60 size sections were used to represent the aerosol size distribution. Size bins are evenly distributed on a logarithmic scale, ranging from the smallest diameter of $1 \mathrm{~nm}$ to the largest diameter of $10 \mu \mathrm{m}$. It is possible to use a different maximum diameter.

The kinetic pre-processor KPP version 1.1 (http://people.cs. vt.edu/ asandu/Software/Kpp) is used to generate Fortran95 code for the chemistry module. The Rosenbrock ROS3 solver
(Sandu et al., 1997) with automatic time step control is used to integrate the differential equation system of gas phase and aqueous phase reactions. The discrete equations describing the change of particle number concentration with time are solved with forward finite differences. The time step for the integration of chemistry and of the aerosol processes is $10 \mathrm{~s}$. Change of number and mass concentration of particles is solved subsequent to the integration of the gas phase/liquid phase chemistry. Due to the use of the kinetic pre-processor, new chemical compounds and reactions can be easily included.

Implementation of the presented aerosol box model into 3dimensional atmospheric transport models is facilitated by the splitting of processes and by the efficient integration of gas 
phase/liquid phase concentrations, particle number and mass concentrations. In the following sections the representation of particles in the model (Section 2.1) and the treatment of the implemented aerosol microphysical processes (Section 2.2) are described in detail. The numerical solution for the temporal evolution of the aerosol size distribution in terms of particle number concentrations and component mass concentrations is presented in Section 2.3.

\subsection{Representation of the high Arctic aerosol size distribution}

According to Covert et al. (1996), the airborne particles collected over the Arctic pack ice area was classified in four different size modes: nucleation (Particle diameter $\left.\left(D_{p}\right) 3-25 \mathrm{~nm}\right)$, Aitken $\left(D_{p}\right.$ $25-80 \mathrm{~nm})$, accumulation $\left(D_{p} 80-1000 \mathrm{~nm}\right)$ and coarse $\left(D_{p}>\right.$ $1000 \mathrm{~nm}$ ). In MONO32, four moving monodisperse size classes of the size distribution are represented: nucleation, Aitken, accumulation and coarse mode (the number of modes in MONO32 is optional and can be prescribed by the user). Particles are placed at the geometric-mean number diameter $\left(\mathrm{GMD}_{\mathrm{n}}\right)$ of the lognormal modes. It is noted that this procedure potentially underestimates the size of the largest pre-existing particles in each mode. Field studies have shown that the marine aerosol is typically an internal mixed aerosol (Bates et al., 1998; Raes et al., 2000). In both MONO32 and MAFOR, the aerosol is assumed to be internally mixed, and all particles in a class (mode or section) are characterized by the same size and the same composition. The composition of particles in any class can change with time due to multi-component condensation and/or due to coagulation of particles. The following particulate composition classes are available in both models: non-sea-salt sulfate (nss- $\mathrm{SO}_{4}^{2-}$ ), ammonium $\left(\mathrm{NH}_{4}^{+}\right)$, nitrate $\left(\mathrm{NO}_{3}^{-}\right)$, methane sulphonate $\left(\mathrm{MSA}_{p}\right)$, (secondary) organics, sea salt and (primary emitted) biological material (X). Simulations are initiated with the measured average particulate mass concentrations (in $\mathrm{ng} \mathrm{m}^{-3}$ ) of non-sea-salt sulphate, $\mathrm{MSA}_{p}$, ammonium, nitrate, organic acids, sea salt and the unknown compound $\mathrm{X}$ in the Aitken, accumulation and coarse modes. The number of initial nucleation mode particles is set to zero. In MAFOR, the initial mass concentrations of the lognormal modes are distributed over the size sections, according to (Jacobson, 2005):

$m_{q, k}=\frac{M_{L, q} \Delta d_{p, k}}{d_{p, k} \sqrt{2 \pi} \ln \sigma_{L}} \exp \left[-\frac{\ln ^{2}\left(d_{p, k} / \mathrm{GMD}_{\mathrm{m}}\right)}{2 \ln ^{2} \sigma_{L}}\right]$,

where $M_{L, q}$ and $\sigma_{L}$ are the mass concentration of the constituents and the band width of the lognormal mode, respectively, $d_{p, k}$ is the diameter of size section $k$ and $\Delta d_{p, k}$ the corresponding diameter width. The initial number concentration in each mode is then matched by varying the geometric-mean mass diameter $G M D_{m}$ in eq. (1).

Index $q\left(q=1, \ldots, N_{C}\right)$ is used throughout the paper to denote the chemical constituents, $N_{C}$ being the number of constituents in the aerosol. Index $k\left(k=1, \ldots, N_{B}\right)$ is used to denote the current size section of the particle and $N_{B}$ is the number of size sections.

\subsection{Processes included in the model}

2.2.1. Multiphase chemistry. The basic gas phase chemistry of MAFOR includes tropospheric photochemistry with optional halogen chemistry (Sander and Crutzen, 1996) and is based on the Module Efficient Calculating the Chemistry of the Atmosphere (MECCA) by Sander et al. (2005). Diurnal variations of photolysis rates are based on Landgraf and Crutzen (1998) using updated data on quantum yield and absorption cross-sections from the Jet Propulsion Laboratory (JPL) Evaluation No. 14 (Sander et al., 2003). DMS gas phase chemistry is taken from the EL CID scheme (EL CID, 2003; Karl et al., 2007) using a revised value for the rate constant of the thermal decomposition of $\mathrm{CH}_{3} \mathrm{SO}_{2}\left(10 \mathrm{~s}^{-1}\right.$, Mellouki et al., 1988). The currently applied DMS chemistry scheme comprises 30 compounds and 65 reactions in the gas phase, and 13 compounds and 39 reactions in the aqueous phase. The liquid phase DMS chemistry mainly treats the oxidation of S(IV) to S(VI)) and involves 5 gas/liquid phase equilibrium constants (Henry's Law constants). Since the liquid phase chemistry of DMSO and $\mathrm{DMSO}_{2}$ remains highly speculative it was not included in the current version. In this study only oxidation of hydrocarbons and DMS with the hydroxyl radical $(\mathrm{OH})$, ozone $\left(\mathrm{O}_{3}\right)$ and the nitrate radical $\left(\mathrm{NO}_{3}\right)$ was considered.

In a system with equilibrium partitioning of gas phase constituents to the aqueous phase of aerosols and clouds, the changes of gas phase and aqueous phase concentrations of compound $i$ with time are described by:

$$
\begin{aligned}
& \frac{d C_{g, q}}{d t}=Q_{g, q}-k_{m, q} L\left(C_{g, q}-\frac{C_{a q, q}}{H_{q}}\right) \\
& \frac{d C_{a q, q}}{d t}=Q_{a q, q}+k_{m, q} L\left(C_{g, q}-\frac{C_{a q, q}}{H_{q}}\right),
\end{aligned}
$$

where $C_{g, q}$ and $C_{a q, q}$ are the gas phase and aqueous phase concentrations of compound $q$, respectively. Both concentrations are given in terms of gas phase units (i.e. $\mathrm{cm}^{-3}$ ). $Q_{g, q}$ and $Q_{a q, q}$ are the respective gas phase and aqueous phase net production terms $\left(\mathrm{cm}^{-3} \mathrm{~s}^{-1}\right), L$ is the liquid water content, $H_{q}$ is the dimensionless Henry coefficient. The transfer of molecules from the gas phase to the aqueous phase and vice versa is treated by the resistance model of Schwartz (1986). The mass transfer coefficient, $k_{m, q}$, is a first-order loss rate constant (in $\mathrm{s}^{-1}$ ) that describes the mass transport of compound $q$ from the gas phase to the aqueous phase and depends on the particle's radius (Schwartz, 1986):

$$
k_{m, q}=\left(\frac{r_{k}^{2}}{3 D_{q}}+\frac{4 r_{k}}{3 c_{m, q} \alpha_{q}}\right)^{-1}
$$


where $D_{q}$ is the gas phase diffusion coefficient (in $\mathrm{m}^{2} \mathrm{~s}^{-1}$ ), $c_{m, q}$ is the molecular speed (in $\mathrm{m} \mathrm{s}^{-1}$ ) and $\alpha_{q}$ is the mass accommodation coefficient of compound $q$ and $r_{k}$ is radius of particle in section $k$. The mass transfer coefficients of partitioning compounds are calculated for Aitken, accumulation and coarse mode. Nucleation mode particles are assumed to be without water. The dimensionless Henry's Law coefficient is defined as:

$H_{q}=\frac{C_{a q, q}}{C_{g, q}}$.

The partitioning coefficient, as dimensionless value, is independent of the liquid water content. It is assumed that the liquid aerosol behaves as an ideal solution and that no formation of solids from the liquid mixture occurs. Aqueous phase partitioning parameters and aqueous phase reactions are adopted from the MECCA chemistry module (Sander et al., 2005). Aqueous phase concentrations are initially set to zero to avoid mass transfer from the liquid aerosol to the gas phase in the beginning of the simulation.

Dry deposition rates and emission rates of relevant gas-phase compounds can be provided in the input files by the user. For strong inorganic, organic acids and water-soluble organic sulphur compounds from DMS oxidation a dry deposition velocity of $1 \mathrm{~cm} \mathrm{~s}^{-1}$ is applied in this study.

2.2.2. Condensation. The molecular flux of the condensing compound depends on the difference between the vapour concentration far away from the particle and its vapour concentration at the particle surface, and on the condensation sink due to pre-existing particles. The rate of condensation/evaporation $I$ of compound $q$ to a particle in section $k$ is equal to (Fuchs and Sutugin, 1970):

$I_{q, k}=\left(48 \pi^{2} v_{k}\right) \times D_{q} \beta_{q, k} v_{g, q}\left[C_{g, q}-S_{q, k}^{\prime} C_{g, e q, q}\right]$,

where $\beta_{q, k}$ is the transitional correction factor, $v_{g, q}$ is the molecular volume of the condensing vapour (in $\left.\mathrm{cm}^{3}\right), C_{g, q}$, is the vapour concentration in the gas phase, $C_{g, e q, q}$, its concentration over a flat solution of the same composition as the particle, and $S_{q, k}^{\prime}$ is the equilibrium saturation ratio of the condensing vapour. Condensation of sulphuric acid and MSA onto particles is considered in all scenarios of this study, while condensation of an organic vapour to the particles is optionally allowed. The effect of hydration of $\mathrm{H}_{2} \mathrm{SO}_{4}$ and MSA on the condensation rate of these vapours is taken into account as described in Karl et al. (2007).

Since the organic vapour $(\mathrm{OV})$ has not yet been identified, we assume that it has the properties of succinic acid, which is one of the three dicarboxylic acids observed in Aitken, accumulation and coarse mode aerosol during the AOE-96 expedition with concentrations ranging from 0.2 to $15 \mathrm{ng} \mathrm{m}^{-3}$. Water-soluble saturated dicarboxylic acids are commonly present in atmospheric aerosols of the marine BL (Kawamura and Usukura, 1993; Kawamura et al., 1996; Mochida et al., 2003). They are thought to originate from the photochemical oxidation of biogenic and anthropogenic hydrocarbons (Jacobson et al., 2000) but the exact formation mechanism is still speculative. It appears that a large fraction of oxalic acid is formed in-cloud through the aqueous phase oxidation of glycolaldehyde originating from the gas-phase oxidation of isoprene (Ervens et al., 2008; Tilgner et al., 2008). The saturation vapour pressure of succinic acid is $3.9 \times 10^{-5} \mathrm{~Pa}$ at $296 \mathrm{~K}$ (Bilde et al., 2003) and, using the temperature dependence given by Bilde et al. (2003), is calculated to be $1.3 \times 10^{-7} \mathrm{~Pa}$ at $270 \mathrm{~K}$, allowing for efficient condensation at cold temperatures. The saturation concentration of the condensable vapour, $C_{g, e q}\left(\mathrm{in}^{-3}\right)$, is derived from saturation vapour pressure $p_{a}^{0}$ (in $\mathrm{Pa}$ ) using the relation $C_{g, e q}=p_{a}^{0} /\left(10^{6} k_{B} T\right)$, where $k_{B}$ is the Boltzmann constant $\left(k_{B}=1.3807 \times 10^{-23} \mathrm{~kg}\right.$ $\mathrm{m}^{2} \mathrm{~s}^{-2} \mathrm{~K}^{-1}$ ). Temperature-dependent expressions for the saturation vapour pressure given by Kreidenweis and Seinfeld (1988a) for MSA, by Kulmala and Laaksonen (1990) for $\mathrm{H}_{2} \mathrm{SO}_{4}$ and by Bilde et al. (2003) for succinic acid were adopted in this work.

The Kelvin (curvature) effect describes the saturation vapour pressure increases over a curved surface relative to a flat surface and is expressed as:

$S_{q, k}^{\prime}=\exp \left(\frac{2 \sigma_{q} M W_{q}}{R T \rho_{L, q} r_{k}}\right)$.

In this study, the Kelvin effect is considered for the condensation/evaporation of sulphuric acid, MSA and organics. Inclusion of the Kelvin effect in particular reduces the condensation flux of vapours to small particles of sizes below $10 \mathrm{~nm}$ diameter. In eq. (6), $M W_{q}$ is the molecular weight of the condensing vapour. $R$ is the universal gas constant $\left(R=8.3144 \mathrm{~kg} \mathrm{~m}^{2} \mathrm{~s}^{-2} \mathrm{~K}^{-1} \mathrm{~mol}^{-1}\right), \sigma_{q}$ is the surface tension (in $\mathrm{kg} \mathrm{s}^{-2}$ ) and $\rho_{L, q}$ is the density of the liquid (in $\mathrm{kg} \mathrm{m}^{-3}$ ). To calculate the Kelvin effect of the condensing organic vapour, surface tension and density of succinic acid are used. We use the temperature-dependent expression for the surface tension of (pure) succinic acid derived by Hyvärinen et al. (2006) based on the method of Macleod-Sugden. The molecular weight of succinic acid is $0.118 \mathrm{~kg} \mathrm{~mol}^{-1}$ and a density value of $1566 \mathrm{~kg} \mathrm{~m}^{-3}$ is used. For MSA, a surface tension of $0.053 \mathrm{~kg} \mathrm{~s}^{-2}$ (Kreidenweis and Seinfeld, 1988a) and a density of the pure liquid of $1507 \mathrm{~kg} \mathrm{~m}^{-3}$ (Wyslouzil et al., 1991a) is used. For $\mathrm{H}_{2} \mathrm{SO}_{4}$, the expressions for surface tension and density from Vehkamäki et al. (2002) using unity mass fraction of $\mathrm{H}_{2} \mathrm{SO}_{4}$ are applied.

Based on the above, the concentrations of a condensable compound $q$ in the gas phase with respect to condensation/evaporation and gas phase chemistry is predicted using the following equation:

$\frac{d C_{g, q}}{d t}=Q_{q}-2 \pi D_{q} \sum_{k=1}^{N_{B}} N_{k} d_{p, k} \beta_{q, k} \times\left[C_{g, q}-S_{q, k}^{\prime} C_{g, e q, q}\right]$.

The first term, $Q_{q}$, is the net gas phase chemical production rate, that is, the sum of production and loss processes in the gas phase. The second term on the right hand side of Eq. (7), represents the condensation/evaporation flux of compound $q$ to the pre-existing particle population as defined with Eq. (5). If $C_{g, e q, q}$ 
is zero, the second term of Eq. (7) describes the condensation sink of the vapour $q$. The condensation sink $C S$ to the aerosol population is defined by,

$C S_{q}=2 \pi D_{q} \sum_{k=1}^{N_{B}} \beta_{q, k} d_{p, k} N_{k}$.

The condensation sink $C S$ is a measure of the rate by which the vapour condenses onto the whole particle population. The transitional correction factor $\beta_{q, k}$ (Fuchs and Sutugin, 1970) is

$\beta_{q, k}=\frac{K n+1}{1+\left(\frac{4}{3 \alpha_{q}}+0.377\right) K n+\frac{4}{3 \alpha_{q}} K n^{2}}$,

where $\alpha_{q}$ is the accommodation (or sticking) coefficient. Accommodation coefficient for sulphuric acid is 0.5 inferred from field studies (Jefferson et al., 1998; Bardouki et al., 2003), and for MSA is 0.13 (De Bruyn et al., 1994). The accommodation coefficient of the organic vapour on particle surfaces is assumed to be equal to unity. The Knudsen number is $K n=\lambda_{v} / r_{k}$, where $\lambda_{v}$ is the mean free path of vapour molecules. A non-iterative solution for the change of the gas phase concentration with time is obtained by making use of the mass balance equation of final aerosol and gas phase concentrations (Jacobson, 2005)

$$
\begin{aligned}
C_{t o t, q}= & C_{g, q}+\sum_{k=1}^{N_{B}} m_{q} \\
C_{g, q, t}= & \frac{C_{g, q, t-\Delta t}+\Delta t \sum_{k=1}^{N_{B}}\left(2 \pi d_{p, k} N_{k, t-\Delta t} D_{q} \beta_{q, k} S_{q}^{\prime} C_{g, e q, q}\right)}{1+\Delta t \sum_{k=1}^{N_{B}}\left(2 \pi d_{p, k} N_{k, t-\Delta t} D_{q} \beta_{q, k}\right)}
\end{aligned}
$$

The condensation rate of condensable vapours in each size bin is calculated each time step. The calculation procedure for mass transfer of vapour molecules to particles follows the mass-conserving Analytical Predictor of Condensation scheme (Jacobson, 2005). Absorption of water by the particles is neglected. Instead the water content of particles in each size bin is estimated using the polynomial expression by Tang and Munkelwitz (1994) for ammonium sulphate aerosols.

2.2.3. Coagulation. Particle coagulation is a process in which small particles (assumed to be spherical) collide with each other and coalesce completely to form larger spherical particles. A semi-implicit solution is applied to coagulation (Jacobson, 2005). The semi-implicit solution yields an immediate volumeconserving solution for coagulation with any time step. Though particle number is not exactly conserved, the error in number concentration reduces when the number of size bins to describe the size distribution is increased.

Brownian coagulation coefficients $K_{k, j}$ between particles in size bin $k$ and $j$ are calculated according to Fuchs (1964). If colliding particles result in a particle that has exactly the same size as particles in section $k$, the particle is attributed to section $k$ and the number concentration of section $k$ increases. In all other cases, particles are redistributed among the nearest sections according to the resulting particle's volume. If particles in section $k$ coagulate with any particles of the other size classes or with each other, the number concentration in section $k$ decreases.

2.2.4. Dry deposition and precipitation scavenging. Sizedependent dry deposition rates are modelled according to Schack et al. (1986) and take into account Brownian diffusion, interception and gravitational settling. Precipitation scavenging is assumed to occur by accretion, that is, incorporation of particles into precipitation-size drops as a result of droplet collision and coalescence. According to Pruppacher and Klett (1978), the scavenging rate for in-cloud removal of particles by accretion can be parameterized as

$\lambda_{w e t}=f_{c} \cdot 3.49 \times 10^{-4} \cdot R^{0.79}$,

where $P R$ is precipitation rate (in $\mathrm{m} \mathrm{s}^{-1}$ ) and $f_{c}$ is the volume fraction occupied by clouds. The typical marine BL volume cloud fraction is $5-10 \%$, and $f_{c}=0.1$ was used. Only in-cloud scavenging is considered. Nucleation mode particles are not scavenged. Precipitation rate can be provided in the input files by the model user and may vary with time.

2.2.5. Nucleation. Based on a review of extensive set of field measurements, Kulmala et al. (2004a) concluded that sulphuric acid is a very likely candidate for atmospheric nucleation. However, the nature of the exact nucleation mechanism(s) remains unknown. In MAFOR, several options for nucleation mechanisms can be chosen. It is generally accepted that the most likely nucleating compounds under tropospheric conditions are $\mathrm{H}_{2} \mathrm{SO}_{4}, \mathrm{H}_{2} \mathrm{O}$ and $\mathrm{NH}_{3}$. Organic vapours may also be directly involved in nucleation through the formation of stable organic acid-sulphuric acid complexes (e.g. Zhang et al., 2004). This possibility is however not considered. In the current implementation growth of newly formed particles to larger sizes can optionally be enhanced by condensation of an arbitrary organic vapour (see Section 2.2.2).

Six nucleation mechanisms are included in this study:

(i) Binary homogeneous nucleation of sulphuric acid-water. Based on the classical, thermodynamically correct, nucleation theory, Vehkamäki et al. (2002) developed a parameterization that holds at temperatures between $230 \mathrm{~K}$ and $305 \mathrm{~K}$ and relative humidity between $0.01 \%$ and $100 \%$. Resulting nucleation rates from this parameterization are within an order of magnitude compared with theoretical values. The parameterization takes into account the effect of hydrate formation (Jaecker-Voirol et al., 1987; Noppel et al., 2002).

(ii) Ternary homogeneous nucleation of sulphuric acid-ammonia-water. Merikanto et al. (2007) revised the classical theory on ternary nucleation of $\mathrm{H}_{2} \mathrm{SO}_{4}-\mathrm{NH}_{3}-\mathrm{H}_{2} \mathrm{O}$ by including the effect of stable ammonium bisulphate formation. Predicted nucleation rates from the revised ternary theory are lowered by many orders of magnitude compared to the 
older ternary model (Napari et al., 2002a), and are in closer agreement to the available experiments. The parameterization of the ternary nucleation by Merikanto et al. (2007) is valid for temperatures above $235 \mathrm{~K}$ and for relative humidity between $5 \%$ and $95 \%$. Using sulphuric acid concentrations of $5 \times$ $10^{4}-10^{9} \mathrm{~cm}^{-3}$ and ammonia mixing ratios of $0.1-1000 \mathrm{pptv}$, no significant nucleation occurs at temperatures above $295 \mathrm{~K}$.

(iii) Ion-mediated nucleation of sulphuric acid-water. Ambient ions are generated continuously, and ubiquitously, by ionization of air through GCR. The ionization rate is about 2 ion pairs $\mathrm{cm}^{-3} \mathrm{~s}^{-1}$ at ground level and increases up to $20-30 \mathrm{~cm}^{-3} \mathrm{~s}^{-1}$ in the upper troposphere (Reiter, 1992). The 11-year cycle of solar activity has a weak effect on the GCR below $8 \mathrm{~km}$ altitude (Bazilevskaya et al., 2008). We adopt a constant ionization rate of $Q_{\mathrm{GCR}}=2.2$ ion pairs $\mathrm{cm}^{-3} \mathrm{~s}^{-1}$ which was found over the oceanic surface at high latitudes (Hensen and van der Hage, 1994). The most significant loss process for charged clusters in the real atmosphere is ion-ion recombination. In this work, a rate coefficient of $k_{i r}=1.0 \times 10^{-6} \mathrm{~cm}^{3}$ $\mathrm{s}^{-1}$ (Loeb, 1960) is used for the recombination process, which is lower than the typically used value of $1.6 \times 10^{-6} \mathrm{~cm}^{3} \mathrm{~s}^{-1}$ (Laakso et al., 2004). A value of $2.0 \times 10^{-6} \mathrm{~cm}^{3} \mathrm{~s}^{-1}$ can be considered an upper limit for this rate. Another loss process is the dissociation (evaporation) of cluster ions. This process is neglected in the current approach. The rate coefficient for the association of a neutral molecule to the ion or charged cluster, $k_{i f}$, is set to $6.0 \times 10^{-10} \mathrm{~cm}^{3} \mathrm{~s}^{-1}$, laboratory experiments indicate an upper limit of $2 \times 10^{-9} \mathrm{~cm}^{3} \mathrm{~s}^{-1}$. We assume that the same rate coefficient applies for all reaction steps. Under quasi steady state conditions for the charged cluster, the nucleation rate from ion-mediated process can be approximated (Yu and Turco, 2001)

$J_{\text {nucl }}=Q_{\mathrm{GCR}}\left(\frac{1}{1+\sqrt{Q_{\mathrm{GCR}}} \sqrt{k_{i r}} / k_{i f} C_{g, \mathrm{H}_{2} \mathrm{SO}_{4}}}\right)^{n_{c}+1}$,

where $n_{c}$ is the number of sulphuric acid molecules in the critical cluster. The wet diameter of a sulphuric acid molecule is roughly $0.65 \mathrm{~nm}$ (Yu and Turco, 2001). With the observed size of stable (neutral and charged) clusters of around $1.5 \mathrm{~nm}$ (Kulmala et al., 2007), we assume that three sulphuric acid molecules are present in a critical cluster $\left(n_{c}=3\right)$. Calculations by $\mathrm{Yu}(2006)$ with an improved ion-mediation nucleation model confirm that under certain average conditions $\left(T=298 \mathrm{~K}, R H=75 \%, 10^{7} \mathrm{~cm}^{-3}\right.$ $\mathrm{H}_{2} \mathrm{SO}_{4}$ ) the nucleation barrier for negative ions is 3-4 sulphuric acid molecules in the cluster. It is around seven molecules for positive ions. Nucleation rates calculated from the presented parameterization are therefore at the higher end of the possible nucleation through the ion-mediated process by GCR.

(iv) Activation of sulphuric acid clusters. Field observations of new particle formation show that during nucleation events, the rate of new particle formation is a function of the sulphuric acid concentration to the power of one or two. To bring the nucleation theorem in agreement with these observations, the critical cluster is predicted to contain one or two sulphuric acid molecules.
This is in contrast to thermodynamic binary nucleation theory which predicts more than 10 sulphuric acid molecules per cluster. Consequently, Kulmala et al. (2006) proposed an activation mechanism based on the concept of activation probability which is commonly used in the heterogeneous nucleation theory. A simple parameterization of the nucleation rate during cluster activation is (Kulmala et al., 2006)

$J_{\text {nucl }}=A\left(C_{g, \mathrm{H}_{2} \mathrm{SO}_{4}}\right)$.

Thus the nucleation rate of $1 \mathrm{~nm}$ particles has a linear dependence on sulphuric acid concentration. In Eq. (14), $A$ is a coefficient that contains details about the nucleation process. In this study, $A$ is taken from field measurements during the BACCI/QUEST IV campaign in Hyytiälä (Riipinen et al., 2007). The median value, $A=2.4 \times 10^{-7} \mathrm{~s}^{-1}$, is used here. The activation mechanism assumes that neutral or ionic clusters containing one sulphuric acid molecule are activated for further growth. In addition to heterogeneous nucleation, the activation may involve the activation of mutually soluble clusters according to nano-Koehler theory (Kulmala et al., 2004b), heterogeneous chemical reactions, or polymerization.

(v) Kinetic nucleation of sulphuric acid. Kulmala et al. (2006) found that observed nucleation events could be explained by assuming kinetic nucleation of sulphuric acid. Kinetic (barrier less) nucleation involves two molecules of sulphuric acid in a critical cluster. A simple parameterization of the nucleation rate during cluster activation is (Kulmala et al., 2006)

$J_{\text {nucl }}=K_{s}\left(C_{g, \mathrm{H}_{2} \mathrm{SO}_{4}}\right)^{2}$.

For kinetic nucleation, the nucleation rate of $1 \mathrm{~nm}$ particles has a power-law dependence on sulphuric acid concentration. The value for $K_{s}$ in Eq. (15) is taken from field measurements during the BACCI/QUEST IV campaign in Hyytiälä (Riipinen et al., 2007). The median value, $K_{s}=3.2 \times 10^{-14} \mathrm{~cm}^{3} \mathrm{~s}^{-1}$, is used here.

(vi) Combined nucleation scheme. A combination of nucleation through ion-mediated nucleation and cluster activation to provide an upper estimate to the nucleation rate can be obtained under tropospheric conditions involving $\mathrm{H}_{2} \mathrm{SO}_{4}$ and $\mathrm{H}_{2} \mathrm{O}$ molecules. The nucleation rate of the combined nucleation scheme is obtained by adding $J_{\text {nисl }}$ calculated by Eq. (13) and Eq. (14).

The nucleation rate calculated using the combined nucleation mechanism (option vi) is referred to as the total/overall nucleation rate throughout the remainder of this paper.

\subsection{Numerical solution of the aerosol dynamics}

The sectional approach approximates the aerosol size distribution by a finite number of size sections whose locations on the diameter coordinate can either vary (using a moving sectional grid) or can be fixed (using a fixed sectional grid) to describe 


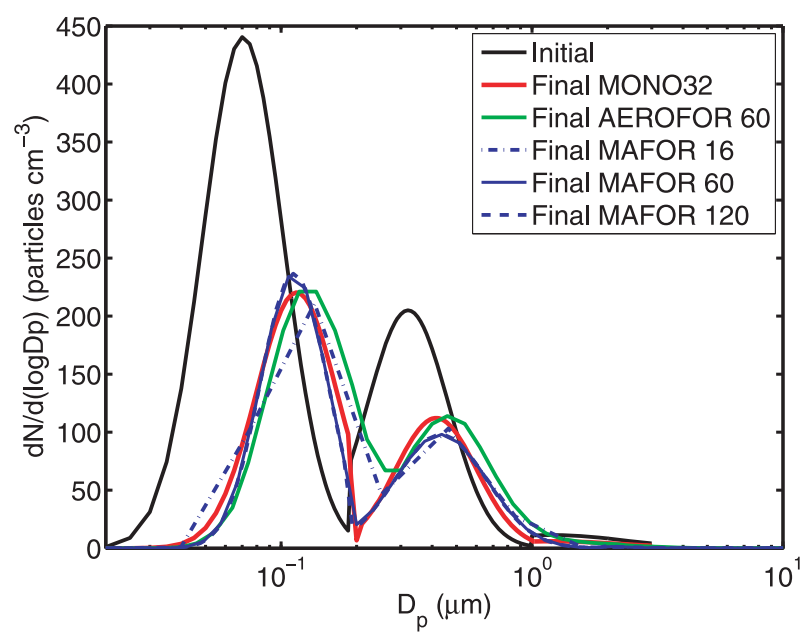

Fig. 1. Initial (solid black line) and final (solid red line) number size distribution from MONO32 and final number size distribution computed by MAFOR (blue lines) using either 16 (dash-dotted), 60 (solid), or 120 (dashed) size bins and by AEROFOR (green line) using 60 size bins. The resulting lines for 60 and 120 size bins almost coincide. Resulting size distributions were obtained from simulations with the marine transport scenario described in Section 3.3. For MONO32, a continuous number size distribution curve was obtained from computed final number concentrations and GMD (wet diameter) of the three monodisperse modes. These, together with initial band width $\left(\sigma_{L}\right)$ and the diameter ranges of the three modes (20-190, $190-1000$ and $1000-10000 \mathrm{~nm}$ ) were then used to calculate $d N / d \log D_{p}$ for each mode (assuming a lognormal distribution). Note the lower cut-off of the graph at $20 \mathrm{~nm}$ and that the nucleation mode was excluded.

the growth of particles. Several different sectional methods have been developed to numerically solve the temporal changes of the aerosol size distribution. The fixed sectional method (Gelbard and Seinfeld, 1980; Tsang and Rao, 1988), which is used in MAFOR, is the most convenient method to treat nucleation, emission, coagulation and particle transport because the particle volume in one size section is always constant. Alternative methods are the full-moving structure (Gelbard, 1990), the hybrid structure (Jacobson and Turco, 1995) and the moving centre structure (Jacobson, 1997). Numerical methods that have been used to solve condensation/evaporation in 3-dimensional models include Bott's method (Dhaniyala and Wexler, 1996) and the partitioned flux integrated semi-Lagrangian method (Nguyen and Dabdub, 2002). All of the methods have some advantages and some disadvantages. It is referred to Jacobson (2005) for a more detailed discussion of the first four structures listed above. A drawback of the fixed sectional method is that the treatment of condensation/evaporation is subject to numerical diffusion. In MAFOR, numerical diffusion is reduced by using a high number of size sections (blue lines in Fig. 1).

The various aerosol dynamical processes are treated by modelling the number concentration and the mass concentration of a chemical constituent for each size section. Due to the logarith- mic spacing of the aerosol size distribution, collision of particles from section $i$ with particles from section $j$ generates an intermediate particle which has a volume between those of two sections $k$ and $k+1$, and needs to be partitioned between the two bins. To this end, an intermediate volume $V_{i, j}$ for the collision of particles and a volume fraction $f$ of the intermediate volume is determined. The intermediate volume, $V_{i, j}$, for the collision of particles from size bin $i$ (volume $v_{i}$ ) with particles from size bin $j$ (volume $v_{j}$ ) is

$V_{i, j}=v_{i}+v_{j}$.

A volume fraction $f_{i, j, k}$ of the intermediate volume that is partitioned to each model bin $k$ is defined as (Jacobson, 2005)

$$
f_{i, j, k}=\left\{\begin{array}{lll}
\frac{v_{k}}{V_{i, j}} & v_{k} \leq V_{i, j}<v_{k+1} & k<N_{B} \\
1-f_{i, j, k-1} & v_{k-1}<V_{i, j}<v_{k} & k>1 \\
1 & V_{i, j} \geq v_{k} & k=N_{B} \\
0 & \text { all other cases. } &
\end{array}\right.
$$

Condensation/evaporation of vapours results in the redistribution of particles between adjacent size sections. Number concentration in size bin $k$ increases when particles from size bin $k-1$ grow by condensation or particles from size bin $k+1$ shrink due to evaporation and it decreases when particles of size bin $k$ change volume by condensation or evaporation.

The change of the particle number concentration in the first section, $N_{1}$, with time occurs by nucleation, coagulation (selfcoagulation and coagulation with particles from other size bins), condensation/evaporation and deposition

$$
\begin{aligned}
\frac{d N_{1}}{d t}= & J_{\text {nисl }}-N_{1} \sum_{j=1}^{N_{B}}\left(1-f_{1, j, 1}\right) K_{1, j} N_{j} \\
& -\left(\frac{\sum_{q=1}^{N_{C}} I_{q, 1}}{v_{2}-v_{1}}\right) N_{1}-\lambda_{\text {dry }} N_{1}-\lambda_{\text {wet }} N_{1},
\end{aligned}
$$

where $J_{\text {nucl }}$ is the nucleation rate (in particles $\mathrm{m}^{-3}$ ), $I$ is the rate of condensation/evaporation (in $\mathrm{m}^{3} \mathrm{~s}^{-1}$ ) as defined in Eq. (5), $K_{1, j}$ refers to the coagulation coefficient of a particle of the first section and a particle in size bin $j$. For the collisions of particles from the first size section with particles from other sections, the volume fraction $f_{1, j, 1}(j>1)$ is zero because the intermediate volume is always larger than the volume of a particle of the first size section. Loss of particles by dry deposition is described by the first-order loss rate constant $\lambda_{\text {dry }}$ (in s ${ }^{-1}$ ) and loss of particles by precipitation scavenging is described by the first-order loss rate constant $\lambda_{\text {wet }}$ (in $\mathrm{s}^{-1}$ ). The third term on the right hand side (RHS) has a negative sign because condensation (flux $I$ is positive) always causes particle number loss from the first size section. 
The change of the particle number concentration, $N_{k}$, with time for all further size bins is given by

$$
\begin{aligned}
& \frac{d N_{k}}{d t}= \frac{1}{v_{k}} \sum_{j=1}^{k}\left(\sum_{i=1}^{k-1} f_{i, j, k} v_{i} K_{i, j} N_{i} N_{j}\right) \\
&-N_{k} \sum_{j=1}^{N_{B}}\left(f_{k, j, k}\right) K_{k, j} N_{j} \\
&-\left(\frac{\sum_{q=1}^{N_{C}} I_{q, k}}{v_{k+1}-v_{k}}\right) N_{k}+\left(\frac{\sum_{q=1}^{N_{C}} I_{q, k-1}}{v_{k}-v_{k-1}}\right) N_{k-1} \\
&-\lambda_{\mathrm{dry}} N_{k}-\lambda_{\text {wet }} N_{k} \\
&(k>1) .
\end{aligned}
$$

The corresponding change of the particle mass concentration of a chemical constituent $q$ in size section $k$ with time is given by

$$
\begin{aligned}
\frac{d m_{q, k}}{d t}= & I_{q, k} N_{k} \rho_{p, k} c_{m}-\left(\frac{\sum_{q=1}^{N_{C}} I_{q, k}}{v_{k+1}-v_{k}}\right) m_{q, k} \\
& +\left(\frac{\sum_{q=1}^{N_{C}} I_{q, k-1}}{v_{k}-v_{k-1}}\right) m_{q, k-1} \\
& +\sum_{j=1}^{k}\left(\sum_{i=1}^{k-1} f_{i, j, k} K_{i, j} m_{q, i} N_{j}\right) \\
& -m_{q, k} \sum_{j=1}^{N_{B}}\left(1-f_{k, j, k}\right) K_{k, j} N_{j} \\
& -\left(\lambda_{d r y}+\lambda_{w e t}\right) m_{q, k} \quad(k>1),
\end{aligned}
$$

where $\rho_{p, k}$ is the density of particles in section $k\left(\mathrm{~kg} \mathrm{~m}^{-3}\right)$ and $c_{m}$ is a conversion factor to convert $\mathrm{kg}$ into $\mathrm{ng}$. The first term on RHS of Eq. (20) describes the effect of condensation (or evaporation) of component $q$ on the total aerosol mass since condensation (or evaporation) of a component results in the growth (or shrinkage) of the mass concentration distribution. The second and third term on RHS take into account that the mass of the individual component increases (or decreases) and consequently the mass concentration distribution moves on the diameter coordinate.

\section{The methods of evaluation of MAFOR using observations in the Arctic}

In order to evaluate the performance of MAFOR, the model was compared with both calculations from MONO32 and with observations utilizing a marine transport scenario (objective 2). Using different nucleation schemes MAFOR was further evaluated with nucleation mode $(<10 \mathrm{~nm}$ diameter) particle number concentrations samples collected at different locations over the Arctic pack ice area north of $80^{\circ} \mathrm{N}$. The observations at 4 (\#1; $2 ; 3 ; 5$ ) out of 20 stations were used in the scenario. Figure 2 shows the geographical location of the stations during the cruise track of the Arctic Ocean Expedition, 1996 (AOE-96). The sun was continuously above horizon at all stations.

\subsection{Brief description of measurement techniques}

An overview of the sample collections made and instrumentation used on board the Swedish icebreaker Oden during the expedition to the central Arctic Ocean in summer of 1996 (AOE-96) is given by Leck et al. (2001). Here, we briefly describe the particle measurements that were used in the present model study. Particle number size distributions were obtained from a differential mobility particle sizing system (DMPS) similar as that described by Heintzenberg et al. (2006). Particle number concentrations in the range $2.7-5 \mathrm{~nm}$ were determined by a pulse height analyser (PHA) attached to a modified TSI-3010 condensation nucleus counter (CNC). Size-resolved chemical composition of the particles was inferred from aerosol mass collected with duplicate high-volume $\left(80 \mathrm{~cm}^{3} \mathrm{~min}^{-1}\right)$ low-pressure 5-stage Berner cascade impactors (BCIs). Substrate material collected with the BCIs was analysed for water-soluble anions and cations using ion chromatography (Leck et al., 2002). Measured concentration data for particulate phase MSA and sulphuric acid (MSA $p$, nss$\mathrm{SO}_{4}^{2-}$ ), ammonium $\left(\mathrm{NH}_{4}^{+}\right.$), sea salt and organics (sum of oxalic acid, succinic acid and glutaric acid) for the observation stations of AOE-96 was adapted from the study of Lohmann and Leck (2005).

\subsection{Meteorological conditions encountered during station \#1; 2; 3; 5 and 20}

Station \#1, July 20-21 (JD 202-203), was located near Bear Island $\left[73.5^{\circ} \mathrm{N} ; 25.5^{\circ} \mathrm{E}\right]$ in the open water. At station $\# 2\left[81.2^{\circ} \mathrm{N}\right.$; $68.5^{\circ} \mathrm{E}$ ], July 25 (JD 207), the icebreaker Oden was situated within partly ice covered waters (20-70\% ice coverage) of the marginal ice zone (MIZ). During station \#3 [83.5 $\left.\mathrm{N} ; 66.0^{\circ} \mathrm{E}\right]$, July 27 (JD 209), the icebreaker was already inside the pack ice region with $80-95 \%$ ice coverage, which also was the case for Station \#5 [86.2 N; 74.4 ${ }^{\circ}$ ], July 31 to August 1 (JD 213-214) and Station \#19 (Ice Camp) [87 N; $143^{\circ} \mathrm{E}$ ], August 21-23 (JD 233-235). Below follows a brief description of the meteorological conditions encountered during each of the stations. For more details we refer to Nilsson and Barr (2001). Station \#1: the period was characterized by a persistent $100 \mathrm{~m}$ deep stratiform cloud layer. The data used were collected during a 4-hour post-weak frontal period of a brief cloud break up. The temperature averaged $8^{\circ} \mathrm{C}$. There was a well-defined mixing layer below $550 \mathrm{~m}$. 
Fig. 2. Map of the icebreaker Oden (thick black line) cruise track during the Arctic Ocean Expedition, 1996 (AOE-96). Stations are indicated with red circles. The grey line illustrates the location of the ice edge zone (adapted from Leck et al., 2001).

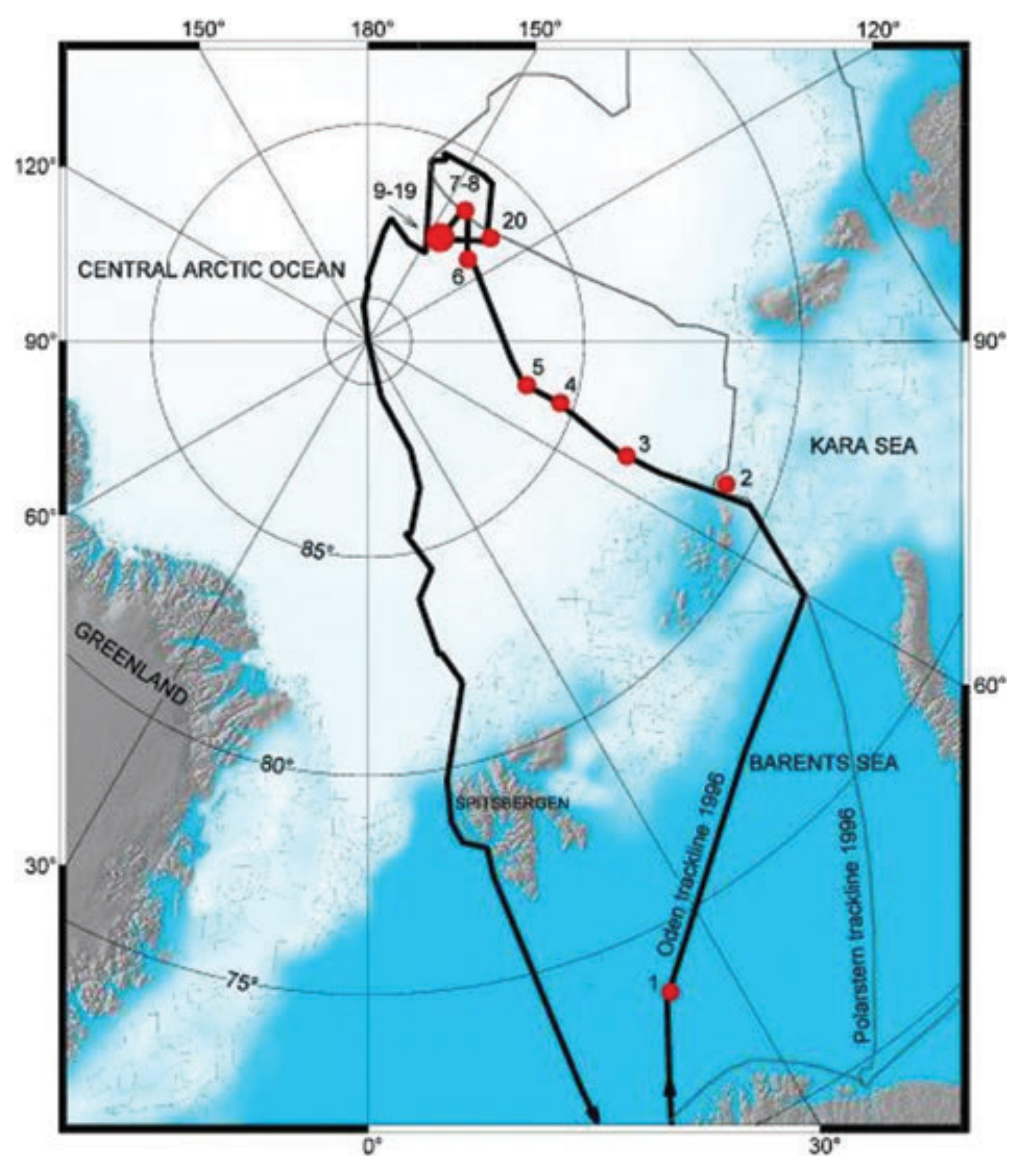

Station \#2: a classic frontal passage passed the location of the icebreaker around 02:00 UTC on July 25. Selected data was collected during the pre-frontal cloud break up when the inversion top reached $300 \mathrm{~m}$. Prior to the frontal passage a surface fog was prevalent until 23:00 UTC on July 24 due to high RH (92\%) and temperatures around $0{ }^{\circ} \mathrm{C}$. The cloud base then began to lift, followed by a complete disappearance of clouds at 23:50 UTC. Around 04:00 UTC on July 25, clouds lowered and thickened and rain showers occurred. Station \#3 and \#5: a weak stationary high pressure ridge dominated the weather during these two stations located within the pack ice. For the entire period, subsiding motion of dried air was observed, causing mainly clear skies with light winds $\left(<4 \mathrm{~m} \mathrm{~s}^{-1}\right)$. Shipboard temperatures varied between -2 and $3{ }^{\circ} \mathrm{C}$. Under these conditions the surface mixed layer was less than $100 \mathrm{~m}$ in depth and was capped with a strong temperature inversion giving a highly stable layer of the order of 90 (\#3) to $200 \mathrm{~m}$ (\#5) deep, which would have prohibited communication between the free troposphere and the surface. The anticyclonic circulation that dominated during stations \#3 and \#5 prevailed again during station \#19 resulting in air masses with clear skies and mainly low wind speeds $\left(<5 \mathrm{~m} \mathrm{~s}^{-1}\right)$ and temperatures between -5 and $-8^{\circ} \mathrm{C}$. In opposite to stations \#3 and \#5, which were sunny and free of local fog and clouds, sta- tion \#19 period had intermittent shallow fogs that persisted for a few hours between sunny intervals.

\subsection{The marine transport scenario}

We defined a marine transport scenario, which follows a Lagrangian approach by simulating an air parcel (containing DMS and particles) that is advected from the DMS source at the MIZ or just south of it (Leck and Persson, 1996a, 1996b) over the pack ice. Although measurements onboard Oden have not always been performed in the same air volume, and thus are not truly Lagrangian, it is according to Nilsson and Leck (2002) possible to use them in a pseudo-Lagrangian approach, if the respective source region of the sampled air volume is known. The time elapsed since the air was last in contact with the open ocean (using current ice maps; National Ice Center, United States) was calculated for each five-day back trajectory reaching the ship's position and pressure level at 6 hourly intervals.

The trajectories were calculated with a 3-D model (McGrath, 1989) at the European Centre of Medium-range Weather Forecasts, UK. The geographical location of the individual stations \#2-5 in the pack ice thus marks the end point for an air parcel 

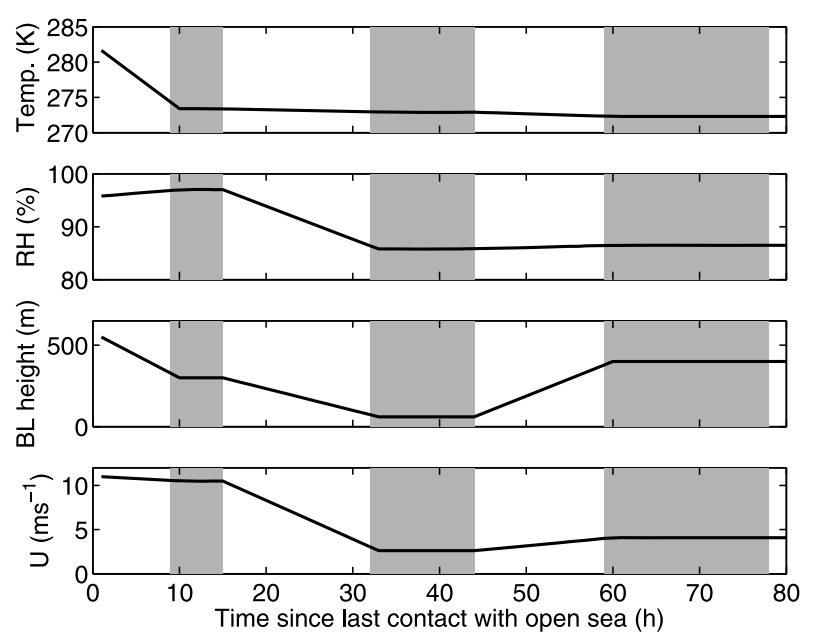

Fig. 3. Meteorological variables from measurements during AOE-96 for $80 \mathrm{~h}$ after last contact with open sea, starting at station \#1.

Temperature, relative humidity and wind speed were measured onboard the icebreaker, boundary layer height was estimated from rawinsondes profile data. Grey shaded boxes indicate periods when the icebreaker Oden was situated at station \#2, 3 and 5. Meteorological data between the station periods was obtained from linear interpolation.

that left the ice edge between 0 and 5 days ago. Figure 3 shows the time series of meteorological variables representative of clear sky conditions during $80 \mathrm{~h}$ since last contact with open sea. Data was interpolated linearly between gaps in the observed time series and used as input values in the model simulation of the marine transport scenario.

\section{Results and discussion}

In Section 4.1, the modelled time series of the concentrations of relevant trace gases as well as gaseous and particulate sulphuric constituents obtained from the MAFOR simulation of the marine transport scenario are compared to the modelled concentrations from MONO32, AEROFOR and to observations. The sensitivity of gaseous and particulate sulphuric constituents towards changes of influential parameters is studied. The sensitivity of the Arctic aerosol size distribution in the marine transport scenario towards main aerosol dynamic processes was investigated in further tests using both MAFOR and AEROFOR. From these tests, it can be concluded that nucleation mode particles are rapidly scavenged by coagulation and by dry deposition during their transport over the pack ice. In Section 4.2 it is investigated how the uncertainties of the initial concentrations of DMS and ozone propagate into modelled concentrations of sulphuric acid and particle number concentrations and possibilities to predict nucleation probability are discussed. Finally, in Section 4.3, the role of a condensing organic vapour is tested and conditions for the enhancement of number concentrations of observable $(>3$ $\mathrm{nm}$ diameter) fresh particles are briefly explored.
Table 2. Modal parameters of the initial aerosol size distribution used in the model comparison

\begin{tabular}{lccl}
\hline Mode & $N\left(\right.$ particles $\left.\mathrm{cm}^{-3}\right)$ & $G M D(\mathrm{~nm})$ & $\sigma_{L}$ \\
\hline Nucleation & 0 & 4 & 1.3 \\
Aitken & 411 & 62 & 1.45 \\
Accumulation & 191 & 242 & 1.45 \\
Coarse & 18.3 & 600 & 1.9 \\
\hline
\end{tabular}

\subsection{Model evaluation with MONO32, AEROFOR and observations}

Simulations of the marine transport scenario $(80 \mathrm{~h})$ were carried out with MONO32, AEROFOR and MAFOR for clear sky conditions. All models included the same aerosol processes and DMS chemistry (EL CID scheme). Partitioning of gaseous constituents to the water phase of aerosol particles was not allowed. Entrainment from the free troposphere was not taken into account. The following emission sources were included: a DMS source of $3 \times 10^{9} \mathrm{~cm}^{-2} \mathrm{~s}^{-1}$ in the first $3 \mathrm{~h}$, emissions of $\mathrm{SO}_{2}$ $\left(4 \times 10^{8} \mathrm{~cm}^{-2} \mathrm{~s}^{-1}\right)$ as well as hydrogen peroxide, $\mathrm{H}_{2} \mathrm{O}_{2},(4 \times$ $\left.10^{9} \mathrm{~cm}^{-2} \mathrm{~s}^{-1}\right)$ in the period from 30 to $60 \mathrm{~h}$ since contact with open sea, and constant emissions of nitrogen dioxide, $\mathrm{NO}_{2}$, of $5 \times 10^{7} \mathrm{~cm}^{-2} \mathrm{~s}^{-1}$ during the whole simulation. Emissions of $\mathrm{SO}_{2}$ and $\mathrm{H}_{2} \mathrm{O}_{2}$ were included to bring the model simulations in closer agreement with the observations of these compounds. Gas phase/aerosol phase concentrations were initialized with observed median values from station \#1 for the compounds these were available. A constant $\mathrm{NH}_{3}$ concentration of $2 \times 10^{10} \mathrm{~cm}^{-3}$ (ca. 800 pptv) was used in the simulation. Table 2 summarizes the modal parameters of the initial aerosol size distribution used in the model comparison.

Results from the comparison are shown in Fig. 4. Observed concentration of DMS decreased steadily during the advection of the air parcel from the open ocean to station \#5. Observed $\mathrm{SO}_{2}$ concentration first increased and then began to decline. As mentioned, $\mathrm{SO}_{2}$ emissions were allowed in the model run during the period at station \#3 in order to match the measurements of $\mathrm{SO}_{2}$ at stations \#3 and \#5. Modelled $\mathrm{OH}$ concentrations showed diurnal variations ranging between $2 \times 10^{5}$ and $1.7 \times$ $10^{6} \mathrm{~cm}^{-3}$ depending on the solar zenith angle. Simulated decay of DMS is faster when using MONO32 and AEROFOR due to the slightly higher oxidation capacity in these simulations. A possible reason for this is the different parameterization of (clear sky) photolysis rates in the models. In MONO32 and AEROFOR, photolysis rates are calculated according to Finlayson-Pitts and Pitts (1986) with updated data for quantum yield and absorption cross-sections from Atkinson et al. (2004); whereas in MAFOR photolysis rates are calculated according to the parameterization by Landgraf and Crutzen (1998). OH levels in the MAFOR simulation were lower (by up to $25 \%$ ) compared to MONO32 and AEROFOR. 

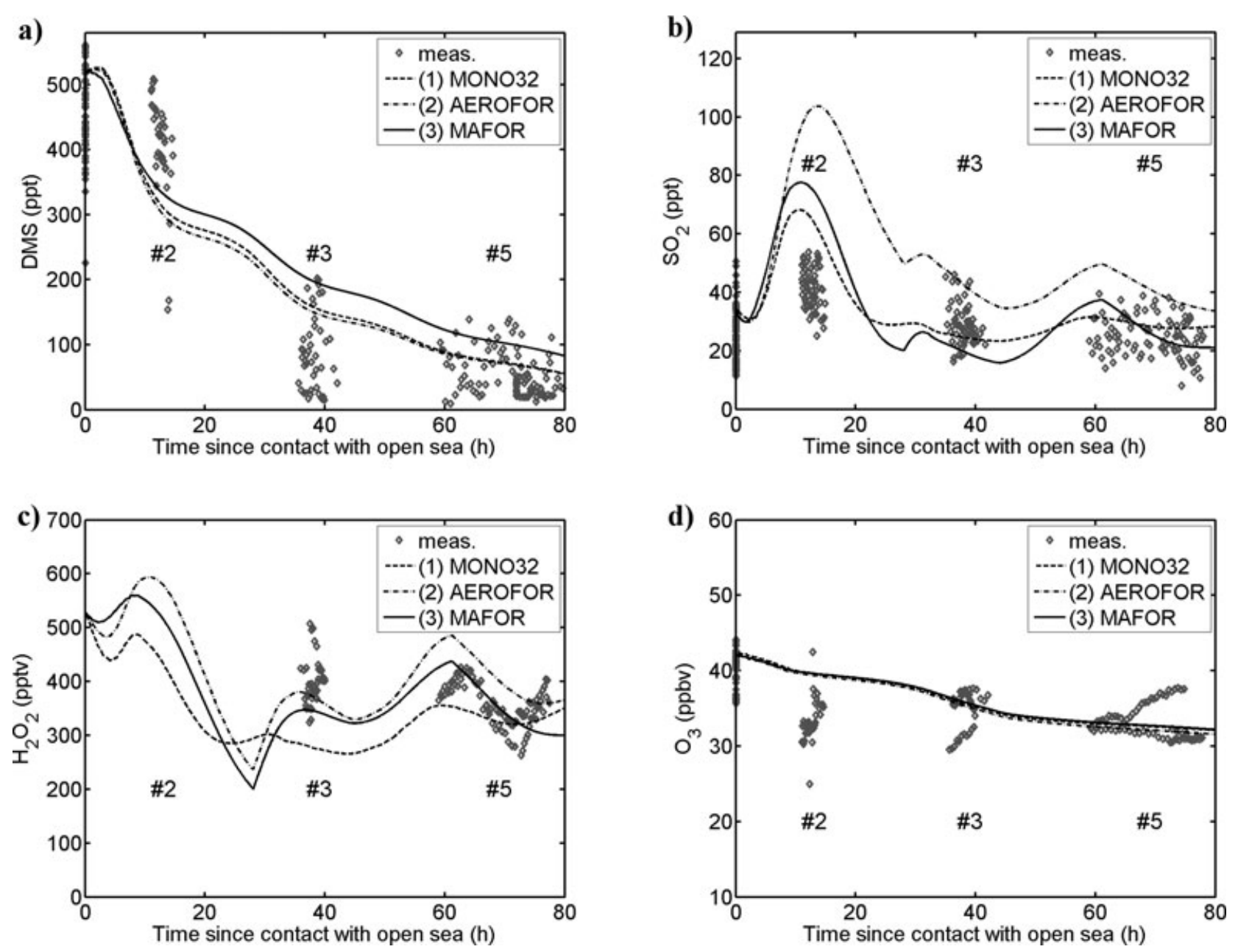

Fig. 4. Marine transport scenario comparison of models and observations. Concentration time series of: (a) DMS, (b) $\mathrm{SO}_{2}$, (c) $\mathrm{H}_{2} \mathrm{O}_{2}$ and (d) $\mathrm{O}_{3}$.

The most significant deviation between the three models is the $\mathrm{SO}_{2}$ concentration during station \#2. $\mathrm{SO}_{2}$ concentrations simulated with MAFOR and with AEROFOR were about $20 \%$ and $35 \%$ higher, respectively, than those from the MONO32 simulation and were roughly a factor of two higher than the observed average $\mathrm{SO}_{2}$ concentrations at station \#2.

Observed concentration of $\mathrm{H}_{2} \mathrm{O}_{2}$ ranged between 250 and 500 pptv at station \#3 and \#5. Observed ozone concentration was rather constant during the transport over the pack ice. A dry deposition velocity of $0.01 \mathrm{~s}^{-1}$ was derived from the slight decrease of $\mathrm{O}_{3}$ with time since contact with open sea and used in the model calculations. This value is in the range of reported ozone deposition velocities $\left(0.006-0.016 \mathrm{~s}^{-1}\right)$ over the snow and ice surface of the central Arctic Ocean (Gong et al., 1997). In general, observed concentrations of long-lived gas phase compounds are relatively well reproduced by the applied models and this is the basis for the further comparison of sulphuric constituents in gas and particle phase.

Concentrations of gaseous $\mathrm{H}_{2} \mathrm{SO}_{4}$ and MSA follow closely the diurnal cycle of $\mathrm{OH}$ during the marine transport scenario.
$\mathrm{H}_{2} \mathrm{SO}_{4}$ concentrations obtained from MAFOR and AEROFOR on the first simulation day were lower than those from MONO32 (Fig. 5a), suggesting that differences in aerosol dynamics, in particular the different representation of aerosols (monodisperse versus sectional), have an effect on modelled $\mathrm{H}_{2} \mathrm{SO}_{4}$ concentrations. MSA concentrations obtained from MAFOR were slightly higher than those from MONO32 and AEROFOR (Fig. 5c). The modelled concentrations of $\mathrm{H}_{2} \mathrm{SO}_{4}$ and MSA ranged up to $1.0 \times 10^{6} \mathrm{~cm}^{-3}$ and $1.8 \times 10^{6} \mathrm{~cm}^{-3}$ at station \#2, respectively. Modelled MSA concentrations are comparable to observed levels in the coastal Antarctic BL (Davis et al., 1998; Jefferson et al., 1998) and somewhat higher than observed levels (1-9 $\times$ $10^{5} \mathrm{~cm}^{-3}$ ) at the South Pole (Mauldin et al., 2001). Modelled $\mathrm{H}_{2} \mathrm{SO}_{4}$ concentrations are in the lower range of observed levels in the coastal Antarctic BL (Davis et al., 1998; Jefferson et al., 1998) but agree well with measured concentrations at the South Pole (Mauldin et al., 2001).

Figures $5 \mathrm{~b}$ and $\mathrm{d}$ show the mass concentrations of nss- $\mathrm{SO}_{4}^{2-}$ and $\mathrm{MSA}_{p}$ in the Aitken mode aerosol during the simulation. Measured particle phase concentrations at station \#1, \#2, \#3 and 

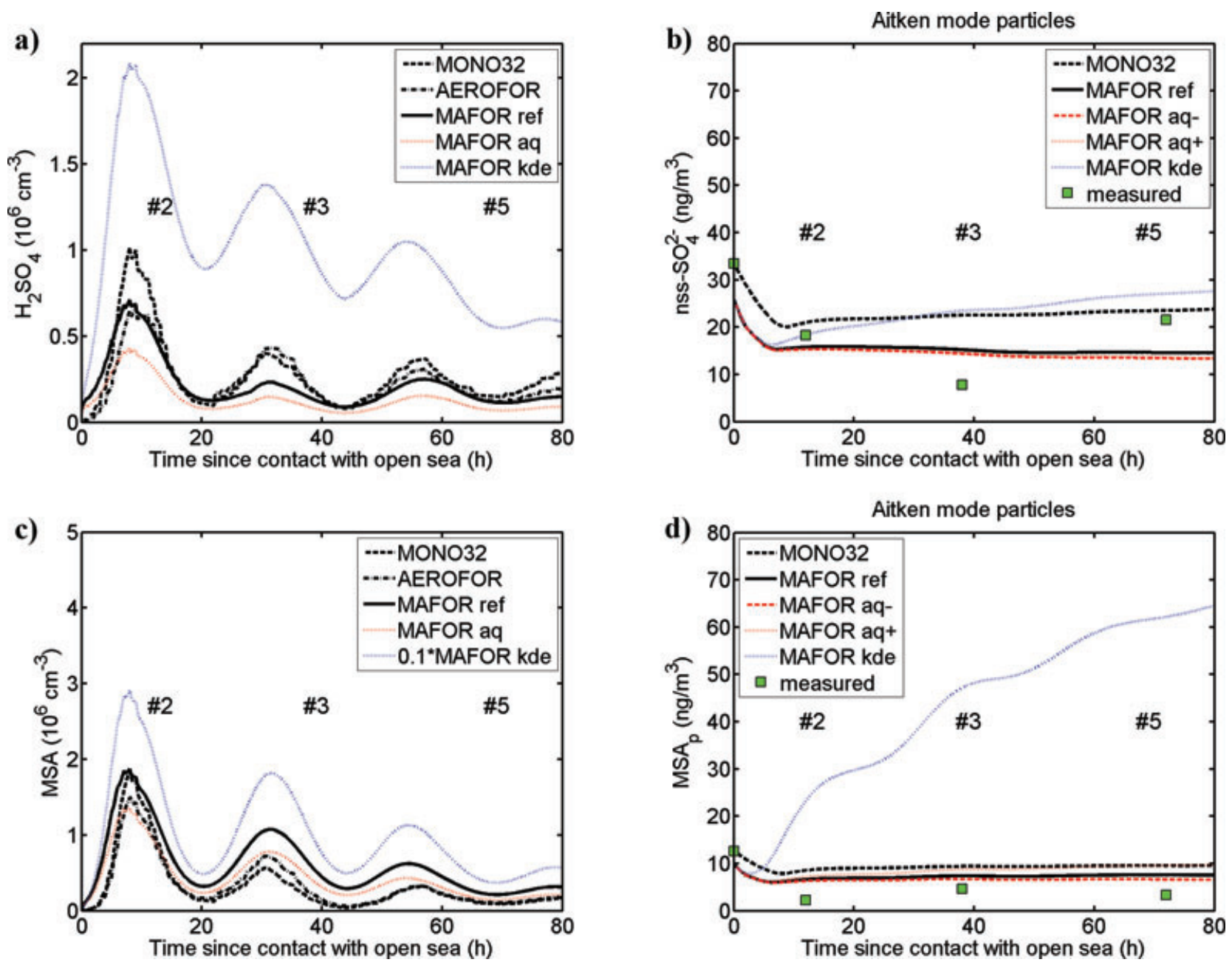

Fig. 5. Concentration time series of gas-phase and particulate phase sulphuric constituents in the marine transport scenario: (a) gaseous $\mathrm{H}_{2} \mathrm{SO}_{4}$, (b) particulate nss- $\mathrm{SO}_{4}^{2-}$ in Aitken mode, (c) gaseous MSA and (d) particulate MSA in Aitken mode. Simulation with MONO32 (dashed black), with AEROFOR (dash-dotted black, only gas-phase constituents), with MAFOR using the reference (ref) configuration (dashed black), with MAFOR (aq) allowing for partitioning to the aqueous phase (red lines), and with MAFOR (kde; dotted blue lines) using the rate constant of $\mathrm{CH}_{3} \mathrm{SO}_{2}$ thermal decomposition given by Kerminen and Leck (2001). Observed nss-SO ${ }_{4}^{2-}$ and $\mathrm{MSA}_{p}$ concentrations in the Aitken mode aerosol obtained during AOE-96 are indicated as green squares. Note that for MAFOR (kde) gaseous MSA concentrations were scaled by a factor of 0.1. For details on the uncertainty tests see text.

\#5 are added for comparison. Simulated particulate concentrations of the two sulphuric constituents with MONO32 (dashed black lines) and MAFOR (solid black lines) are comparable and match the observations.

To demonstrate, how uncertainties of the most sensitive parameters influence the modelled results of gaseous sulphuric constituents as well as of nss- $\mathrm{SO}_{4}^{2-}$ and $\mathrm{MSA}_{p}$, two tests were carried out with the MAFOR model. In a first test, partitioning of gas phase constituents to the aqueous phase of the aerosol was allowed, simulation MAFOR (aq), and in a second test, the value of the rate constant of the thermal decomposition of methylsulphonyl radical $\left(\mathrm{CH}_{3} \mathrm{SO}_{2}\right)$ provided by Kerminen and Leck (2001) was used, simulation MAFOR (kde).
Allowing for partitioning to the aqueous phase reduced the gas phase concentrations of $\mathrm{H}_{2} \mathrm{SO}_{4}$ and MSA by up to $50 \%$ (dotted red lines in Figs 5a and c) compared to the reference simulation (termed MAFOR (ref) in Fig. 5). As mentioned in Section 2 , the possible conversion of aqueous phase constituents into solid constituents is not yet implemented in MAFOR. In order to make a conclusion about the change of particulate concentrations due to the conversion of $\mathrm{SO}_{2}$ into sulphate in the aqueous phase, two extreme cases were considered. To obtain the minimum particulate concentration, we assumed that no conversion of dissolved $\mathrm{SO}_{2}$ into sulphate took place [dashed red lines in Figs $5 \mathrm{~b}$ and d, MAFOR (aq-)] and to obtain the maximum particulate concentration, we assumed that $100 \%$ of dissolved $\mathrm{SO}_{2}$ 
was converted into sulphate [dotted red lines in Figs $5 \mathrm{~b}$ and d, MAFOR (aq+)]. The result from the partial conversion should lie between the two curves. However, the simulations suggest that reactive uptake of $\mathrm{SO}_{2}$ to Aitken mode aerosol is negligible in the marine transport scenario, in line with the previous study by Karl et al. (2007). Due to the partitioning of acid gas phase constituents Aitken mode aerosol pH decreased to values of 3-4 in simulation MAFOR (aq) (not shown). Under these conditions, $\mathrm{H}_{2} \mathrm{O}_{2}$ is the main oxidant in the liquid phase of Aitken mode aerosol, but the oxidative conversion of $\mathrm{SO}_{2}$ by $\mathrm{H}_{2} \mathrm{O}_{2}$ is not efficient enough to affect the growth of particles significantly (Pirjola et al., 1999b).

The methylsulphonyl radical, $\mathrm{CH}_{3} \mathrm{SO}_{2}$, is an important intermediate in DMS oxidation schemes. The rate constant of the thermal decomposition of $\mathrm{CH}_{3} \mathrm{SO}_{2}$ is a very sensitive parameter. Its value is highly uncertain: reported values range from $2 \times$ $10^{-3}$ to $500 \mathrm{~s}^{-1}$ (at $280 \mathrm{~K}$ ). The rate constant affects directly the yield of $\mathrm{SO}_{2}$ from the oxidation of DMS and indirectly the yield of gaseous and particulate $\mathrm{H}_{2} \mathrm{SO}_{4}$ and MSA. In our earlier study, we demonstrated that the production of MSA is strongly controlled by the thermal decomposition of $\mathrm{CH}_{3} \mathrm{SO}_{2}$ rate constant (Karl et al., 2007). Using the rate constant parameterization given by Kerminen and Leck (2001), $6 \times 10^{12} \exp (-9062 / T)$ (corresponding to $0.05 \mathrm{~s}^{-1}$ at $280 \mathrm{~K}$ ), instead of the currently applied value of $10 \mathrm{~s}^{-1}$ (Mellouki et al., 1988), gas phase concentrations of $\mathrm{H}_{2} \mathrm{SO}_{4}$ and MSA increase by a factor of about 2.5 and 12, respectively (MAFOR (kde) simulation, dotted blue lines in Figs 5a and c), compared to the reference simulation. As can be seen in Fig. 5d, resulting concentrations of $\mathrm{MSA}_{p}$ in the Aitken mode by far exceed observed concentrations, clearly indicating that the absolute value proposed by Kerminen and Leck (2001) is not adequate. However, their derived activation energy of $18 \mathrm{kcal} \mathrm{mol}^{-1}$ might still be valid.

Figure 1 shows the resulting final particle number size distributions of the marine transport scenario after $80 \mathrm{~h}$ from the simulation with MONO32 (red line), AEROFOR (green line) and MAFOR (solid blue line). Despite largely different representations of the aerosol in the three models, good agreement of the modelled final number size distributions is found. Resulting final total number concentrations of $>3 \mathrm{~nm}$ diameter size particles deviated less than $15 \%$ among the three models. Aitken mode and accumulation mode diameters of the final distribution obtained from MAFOR and AEROFOR deviated by $20 \%$ and $12 \%$, respectively.

In a further set of tests, the marine transport scenario described in Section 3.3 was used to study the sensitivity of the particle number size distribution with respect to aerosol processes. As described earlier, the model approach was to follow an air parcel that is advected from the DMS source region in the open waters at the MIZ and south thereof into the arctic pack ice. The photochemical oxidation of DMS provides precursor compounds for condensation and nucleation. Nucleation of sulphuric acid particles was treated according to the kinetic nucleation mechanism.
Table 3. Modal parameters of the initial aerosol size distribution used to test the sensitivity towards aerosol processes with MAFOR and AEROFOR

\begin{tabular}{lccc}
\hline Mode & $\begin{array}{c}N \\
\left(\text { particles } \mathrm{cm}^{-3}\right)\end{array}$ & $\begin{array}{c}G M D_{m}(\mathrm{~nm}) \\
(\text { dry })\end{array}$ & $\sigma_{L}$ \\
\hline Nucleation & 100 & 4 & 1.45 \\
Aitken & 403 & 79 & 1.37 \\
Accumulation & 191 & 403 & 1.53 \\
Coarse & 1.8 & 1500 & 1.61 \\
\hline
\end{tabular}

Table 3 summarizes the modal parameters of the initial aerosol size distribution used in the test.

All model runs of the aerosol process sensitivity test were done using the two sectional models, MAFOR and AEROFOR. Certain aerosol dynamics processes have been switched off during some of the runs. Figure 6 shows initial number size distribution (grey line), distributions during the simulation after each $8 \mathrm{~h}$ obtained using MAFOR (i.e. 9 curves, shown as dashed grey lines) and the final size distribution after $80 \mathrm{~h}$ from the MAFOR model (black line) and from AEROFOR (red dashed line).

Considering the main aerosol processes (nucleation, coagulation, condensation, dry deposition), the final size distribution (Fig. 6a) showed a decrease of Aitken mode particle numbers. Nucleation produced particles with diameter $<3 \mathrm{~nm}$ during the simulation. Nucleation mode particles were rapidly lost by coagulation scavenging to the Aitken, accumulation and coarse modes (coagulation sink was $2-3 \times 10^{-3} \mathrm{~s}^{-1}$ ) and by dry deposition.

If coagulation is switched off, the Aitken mode changed only slightly throughout the simulation (Fig. 6b). In this simulation, particle loss only occurred by dry deposition. Removal of nucleation mode and Aitken mode particles by dry deposition was faster in the simulation using MAFOR than in the simulation using AEROFOR. Available sulphuric acid vapour was mostly consumed by condensation to pre-existing particles (sulphuric acid condensation sink was $4-5 \times 10^{-3} \mathrm{~s}^{-1}$ in the MAFOR simulation) and to a certain extent was involved in nucleation of fresh particles. In contrast to the simulation using MAFOR, nucleation mode particles $(>3 \mathrm{~nm}$ ) were present after $80 \mathrm{~h}$ in the simulation using AEROFOR. Reasons for this discrepancy are differences in the removal of nucleation mode particles by dry deposition and differences in the condensational growth due to different gas phase $\mathrm{H}_{2} \mathrm{SO}_{4}$ production rates.

On the other hand, if condensation is switched off, nucleation is much stronger, because essentially all sulphuric acid vapour is available for nucleation (Fig. 6c). Total number concentrations of $<3 \mathrm{~nm}$ particles was rather high at the end of this simulation (about 5500 particles $\mathrm{cm}^{-3}$ ). However, freshly nucleated particles did not grow further and remained at sizes $<3 \mathrm{~nm}$ during 

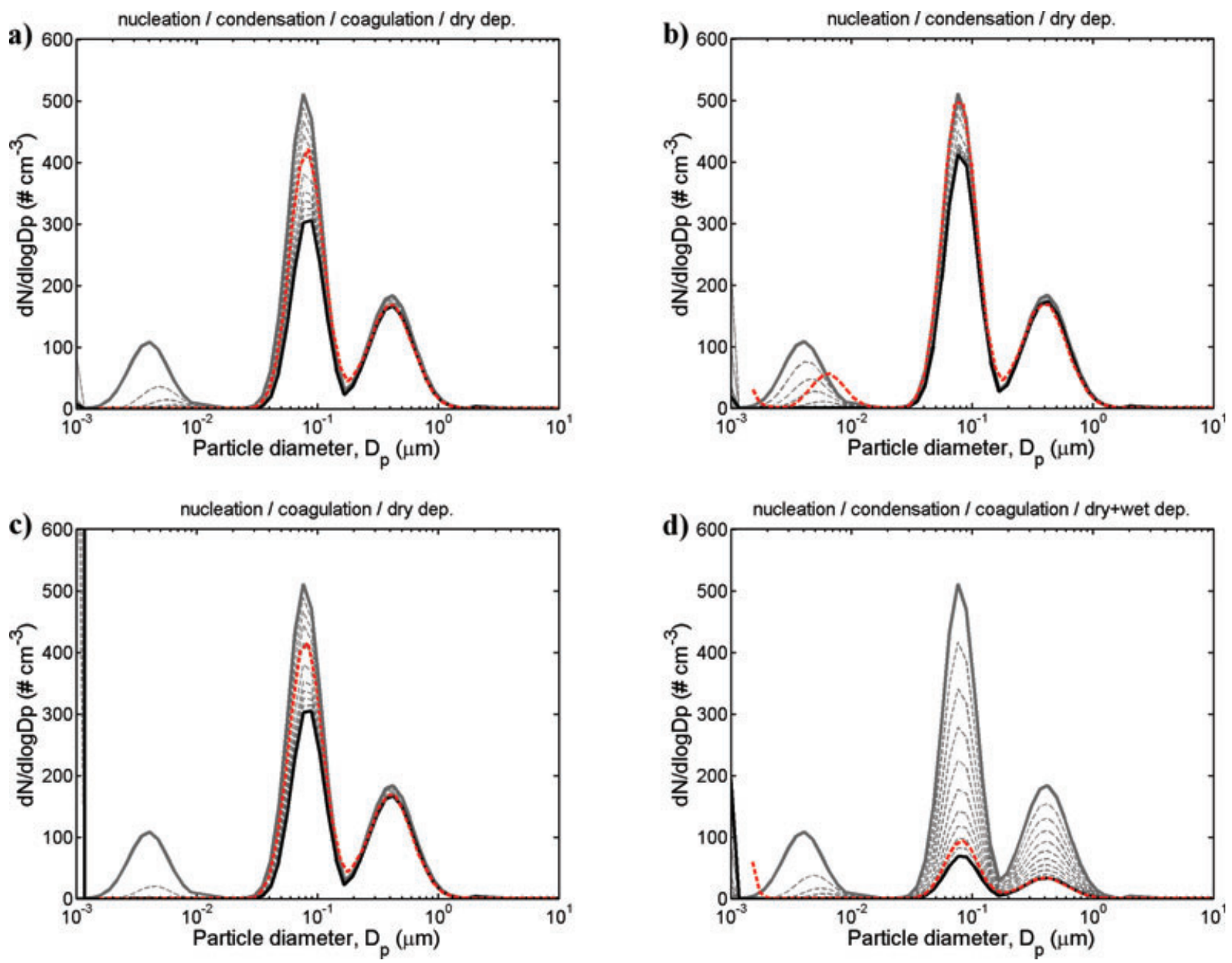

Fig. 6. Test of aerosol processes with MAFOR during the simulation of the marine transport scenario: (a) nucleation/condensation/coagulation/dry deposition, (b) no coagulation, (c) no condensation, (d) all processes including wet deposition with a constant precipitation rate. Grey line: initial number distribution, black line: final distribution using MAFOR, red dashed line: final distribution using AEROFOR, dashed grey lines: snap shots of the distributions after each $8 \mathrm{~h}$ using MAFOR. Note that the smallest diameter of the AEROFOR size distributions is $1.5 \mathrm{~nm}$.

the simulation. Existing nucleation mode particles $>3 \mathrm{~nm}$ were rapidly scavenged by coagulation and dry deposition.

If in addition to the main aerosol processes also wet scavenging of particles is taken into account (using a constant precipitation rate of $0.1 \mathrm{~mm} \mathrm{~h}^{-1}$ ), both Aitken and accumulation mode particle numbers are largely reduced during the simulation (Fig. 6d). Calculated nucleation rate using the kinetic nucleation scheme followed the diurnal cycle of $\mathrm{H}_{2} \mathrm{SO}_{4}$ concentrations and increased from $3 \times 10^{-4} \mathrm{~cm}^{-3} \mathrm{~s}^{-1}$ to $5 \times 10^{-3} \mathrm{~cm}^{-3} \mathrm{~s}^{-1}$ between 40 and $80 \mathrm{~h}$ of the simulation. Due to the simultaneous decrease of the condensation sink (from $9 \times 10^{-4} \mathrm{~s}^{-1}$ to $5 \times 10^{-4} \mathrm{~s}^{-1}$ ), a higher number of nucleated particles with diameter $<3 \mathrm{~nm}$ were present after $80 \mathrm{~h}$ than in the simulation without wet scavenging (Fig. 6a).

Aerosol size distributions computed by the two sectional models MAFOR and AEROFOR are found to be in overall agreement for the different aerosol process sensitivity cases. The response of the modelled size distributions towards selected aerosol processes is similar for both models. Differences of total number concentrations of $>3 \mathrm{~nm}$ diameter sized particles after the $80 \mathrm{~h}$ simulation were less than $25 \%$ in all cases. Both MAFOR and AEROFOR predict that nucleation mode particles have been scavenged after $10 \mathrm{~h}$ of the simulation when all main aerosol processes are considered.

\subsection{Prediction of nucleation probability}

In the reference simulation (MAFOR(ref)) the kinetic nucleation scheme was applied. In a further set of simulations with MAFOR different nucleation schemes were tested using the marine transport scenario as described in Section 4.1. Both classical binary and ternary nucleation failed to predict nucleation in the 


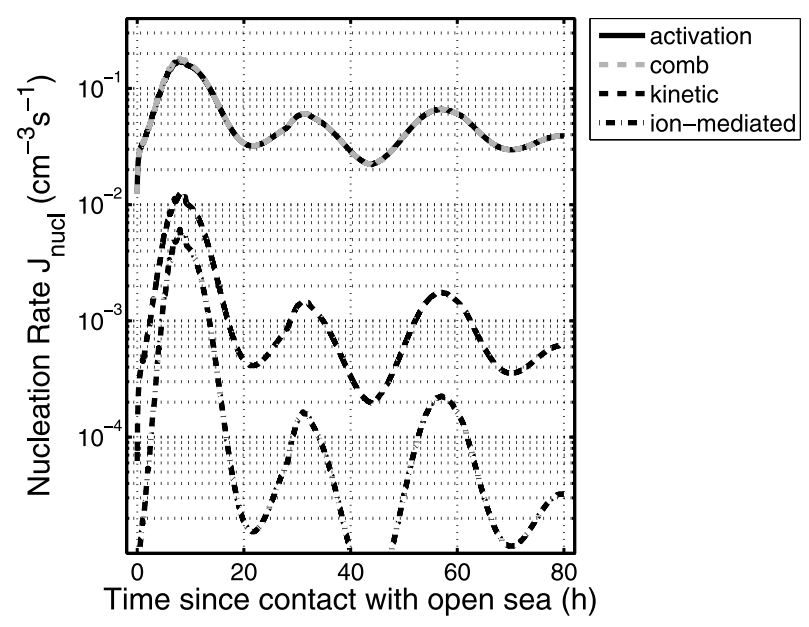

Fig. 7. Modelled nucleation rate, $J_{\text {nucl }}$, from MAFOR simulations using different nucleation schemes in the marine transport scenario. Modelled nucleation rates using cluster activation (activation, solid line) and combined nucleation (comb, dashed grey line) almost coincide.

marine transport scenario. Classical binary and ternary nucleation rates were calculated to be zero $\left(J_{\text {nucl }}=0 \mathrm{~cm}^{3} \mathrm{~s}^{-1}\right)$ due to reduced availability of sulphuric acid and abundance of preexisting particles. The onset temperature for ternary nucleation was calculated to be $242 \mathrm{~K}$ for the given relative humidity and $\mathrm{H}_{2} \mathrm{SO}_{4}$ and $\mathrm{NH}_{3}$ concentrations, about $30-35^{\circ}$ below the temperatures in the scenario. Highest nucleation rates resulted from the cluster activation scheme, ranging up to $0.21 \mathrm{~cm}^{-3} \mathrm{~s}^{-1}$, as expected due to the linear dependence of the computed nucleation rate on sulphuric acid concentrations (solid line in Fig. 7). Ionmediated nucleation produced only few new particles (less than 20 particles $\mathrm{cm}^{-3}$ ) and nucleation rates were below $10^{-2} \mathrm{~cm}^{-3}$ $\mathrm{s}^{-1}$. Kinetic nucleation of sulphuric acid was slightly more efficient than ion-mediated nucleation.

In the combined nucleation scheme (dashed grey line in Fig. 7 and Fig. 8), nucleation rates are calculated as the sum of cluster activation and ion-mediation nucleation rates. In the marine transport scenario, the difference between nucleation rates from cluster activation and combined nucleation is negligible. The contribution of ion-mediated nucleation to the overall number concentration of new particles is less than $2 \%$ (Fig. 8; dashdotted line).

Total number concentration of nucleation mode particles was in the order of 100-400 particles $\mathrm{cm}^{-3}$ when using the activation or combined nucleation schemes, and was below 50 particles $\mathrm{cm}^{-3}$ when using the kinetic or ion-mediated nucleation schemes (Fig. 8). Independent of the chosen nucleation mechanism, newly formed nucleation mode particles remained at sizes below $3 \mathrm{~nm}$ diameter due to the limited availability of sulphuric acid.

The choice of the initial concentrations of DMS and $\mathrm{O}_{3}$ is expected to strongly affect predicted sulphuric acid concentra-

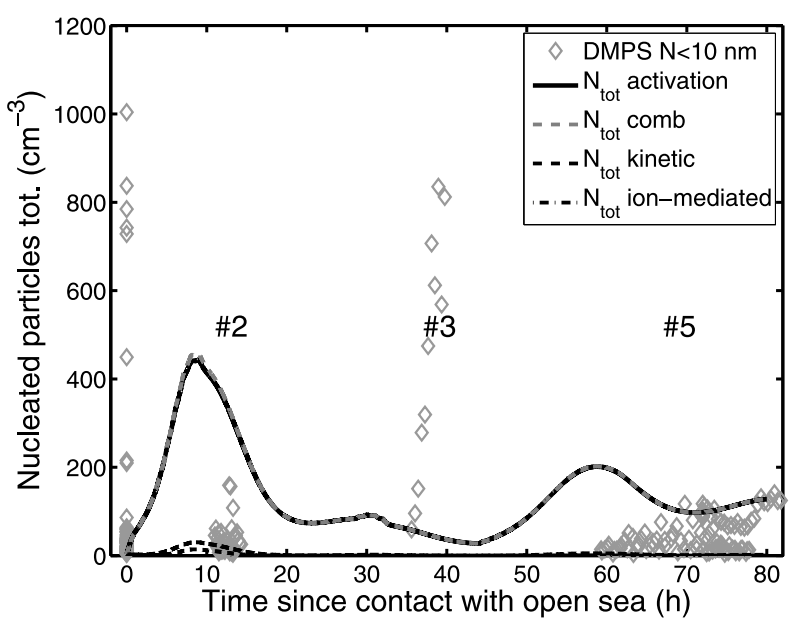

Fig. 8. Modelled total nucleation mode number concentrations $\left(N_{t o t}\right)$ from MAFOR simulations using different nucleation schemes in the marine transport scenario. Grey diamonds indicate number concentration of particles with sizes $<10 \mathrm{~nm}$ observed by DMPS.

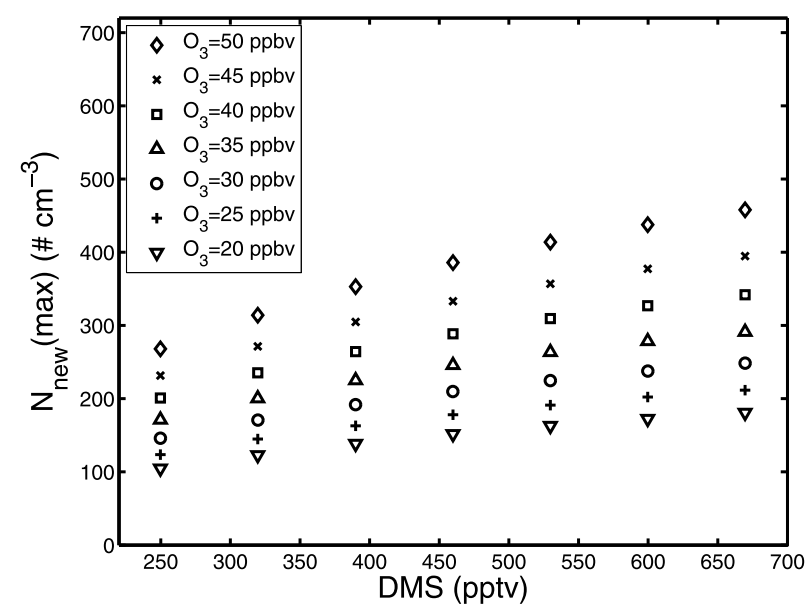

Fig. 9. Modelled daily maximum number concentrations of nucleated particles $\left(N_{\text {new }}(\max )\right)$ from steady state simulations using different DMS and $\mathrm{O}_{3}$ concentrations.

tions and consequently also number concentrations of nucleated particles. Figures $4 \mathrm{a}$ and d show a considerable spread of measured concentrations of DMS and $\mathrm{O}_{3}$ at station \#1. A set of $7 \times 7$ runs with a simulation duration of $52 \mathrm{~h}$ was performed with the MAFOR model using initial DMS concentrations in the range of 250-670 pptv (steps of $70 \mathrm{pptv}$ ) and initial $\mathrm{O}_{3}$ concentrations in the range of 20-50 ppbv (steps of $5 \mathrm{ppbv}$ ). Meteorological parameters were held constant $(T=270 \mathrm{~K}, R H=94 \%$, BL height: $300 \mathrm{~m}$ ), no emissions were included, and concentrations of DMS and $\mathrm{O}_{3}$ were kept at their respective initial values. The combined nucleation scheme was applied. Test simulations showed that short-lived compounds and number concentrations of new particles had reached a steady state after 24 h. Figure 9 shows relationships between DMS concentration and the daily 
maximum number concentration of nucleated particles $\left(N_{\text {new }}(\max )\right)$ which are almost linear for a given $\mathrm{O}_{3}$ concentration. Linear relationships were also found between DMS and the maximum daily sulphuric acid concentration (not shown).

Nucleation rates calculated using the combined nucleation scheme are approximately proportional to sulphuric acid concentration [Eq. (14)] due to the negligible contribution from ion-mediated nucleation. Sulphuric acid is mainly formed in the reaction between $\mathrm{OH}$ radicals and $\mathrm{SO}_{2}$ produced in the reaction chain of the $\mathrm{OH}$-initiated oxidation of DMS, via

(R1) $\mathrm{SO}_{2}+\mathrm{OH} \rightarrow \mathrm{HSO}_{3}$

(R2) $\mathrm{HSO}_{3}+\mathrm{O}_{2} \rightarrow \mathrm{SO}_{3}$

(R3) $\mathrm{SO}_{3}+\mathrm{H}_{2} \mathrm{O} \rightarrow \mathrm{H}_{2} \mathrm{SO}_{4}$.

There is also a direct formation route of $\mathrm{SO}_{3}$ in the reaction chain of DMS

(R4) $\mathrm{CH}_{3} \mathrm{SO}_{3}+M \rightarrow \mathrm{SO}_{3}+\mathrm{CH}_{3}$.

However, sensitivity analysis using the EL CID DMS scheme has shown earlier that $\mathrm{H}_{2} \mathrm{SO}_{4}$ concentrations are not sensitive toward reaction (R4) under arctic conditions. In the remote air of the Arctic, the most important source of $\mathrm{OH}$ radicals is the $\mathrm{UV}$ photolysis $(\lambda<320 \mathrm{~nm}$ ) of ozone and the subsequent reaction of excited $\mathrm{O}\left({ }^{1} \mathrm{D}\right)$ atoms with water vapour

(R5) $\mathrm{O}_{3}+h v \rightarrow \mathrm{O}_{2}+\mathrm{O}\left({ }^{1} \mathrm{D}\right)$

(R6) $\mathrm{O}\left({ }^{1} \mathrm{D}\right)+\mathrm{H}_{2} \mathrm{O} \rightarrow 2 \mathrm{OH}$.

Increased levels of $\mathrm{O}_{3}$ lead to increased production of $\mathrm{OH}$ radicals which in turn enhances the rate of DMS oxidation and consequently also the conversion of $\mathrm{SO}_{2}$ into sulphate. In reaction sequence (R5) and (R6) two $\mathrm{OH}$ radicals are generated per molecule ozone that undergoes UV photolysis and thus the dependence of sulphuric acid concentrations on ozone levels can be expected to be quadratic. Indeed a quadratic dependence of the maximum daily sulphuric acid concentration on $\mathrm{O}_{3}$ concentrations was found in this test for a given DMS concentration (not shown). Note, that increased $\mathrm{O}_{3}$ levels do not affect the $\mathrm{SO}_{2}$ oxidation rate through reaction (R1) because $\mathrm{SO}_{2}$ is already a result of the DMS oxidation chain mechanism.

For the given range of DMS and $\mathrm{O}_{3}$ concentrations, maximum daily concentrations of sulphuric acid concentration and nucleated particle numbers $\left(N_{\text {new }}\right)$ vary from $2.0 \times 10^{5}$ to $8.5 \times$ $10^{5} \mathrm{~cm}^{-3}$ and from 100 to $460 \mathrm{~cm}^{-3}$, respectively. The estimated spread of initial $\mathrm{O}_{3}$ and DMS concentrations in the marine transport scenario simulation (Section 4.1 ) is about $\pm 5 \mathrm{ppbv}$ and \pm 50 pptv, respectively. Thus the uncertainty of modelled $\mathrm{H}_{2} \mathrm{SO}_{4}$ gas phase concentration and number concentration of nucleated particles is estimated to be $20 \%$ and $21 \%$, respectively.

Temperature is another key parameter that modifies calculated numbers of nucleated particles. In Table 4 modelled $N_{\text {new }}$
Table 4. Modelled maximum daily concentration of nucleated particle numbers (particles $\mathrm{cm}^{-3}$ ) for varying $\mathrm{O}_{3}$ concentration at three different temperatures (260, 265 and $270 \mathrm{~K})$ and 670 pptv DMS obtained in steady state calculations with MAFOR.

\begin{tabular}{lccc}
\hline $\begin{array}{l}\mathrm{O}_{3} \text { conc. } \\
\text { (ppbv) }\end{array}$ & $260 \mathrm{~K}$ & $265 \mathrm{~K}$ & $270 \mathrm{~K}$ \\
\hline 20 & 141 & 161 & 181 \\
25 & 156 & 184 & 212 \\
30 & 181 & 212 & 248 \\
35 & 208 & 245 & 291 \\
40 & 239 & 284 & 342 \\
45 & 274 & 337 & 395 \\
50 & 313 & 376 & 458 \\
\hline
\end{tabular}

is shown for three temperatures $(260,265,270 \mathrm{~K})$ at $670 \mathrm{pptv}$ DMS and with $\mathrm{O}_{3}$ varying from 20 to 50 ppbv. Temperature affects the production of $\mathrm{H}_{2} \mathrm{SO}_{4}$ in the oxidation of DMS in a non-linear way. At low temperatures, the reaction between $\mathrm{OH}$ and DMS predominantly proceeds via the addition channel, while with increasing temperature the abstraction channel becomes increasingly competitive. At about $280 \mathrm{~K}$ the addition and abstraction pathways become equally important (Karl et al., 2007); this fundamentally changes the chemical regime for the production of $\mathrm{H}_{2} \mathrm{SO}_{4}$. Thus the near linear relationship between DMS and $N_{\text {new }}$ strictly applies only for temperatures below $0{ }^{\circ} \mathrm{C}$.

The found relationships between $\mathrm{DMS}, \mathrm{O}_{3}$, temperature and $N_{\text {new }}(\max )$ could be further expanded to derive a simple proxy for nucleation probability valid for the remote polar and arctic $\mathrm{BL}$. To this end it is necessary to consider the condensation sink [defined in Eq. (8)] since condensation and nucleation compete for available sulphuric acid. In steady state, ignoring liquid phase uptake and dry deposition, the concentration of $\mathrm{H}_{2} \mathrm{SO}_{4}$ available for nucleation is roughly

$C_{g, \mathrm{H}_{2} \mathrm{SO}_{4}} \approx \frac{Q_{g, \mathrm{H}_{2} \mathrm{SO}_{4}}}{C S_{\mathrm{H}_{2} \mathrm{SO}_{4}}}$

With the help of multivariate analysis it might be possible to derive an expression for the prediction of nucleation probability depending on DMS, $\mathrm{O}_{3}$, temperature and condensation sink. Unfortunately, at current no measured time series of gaseous sulphuric acid exists in the Arctic to evaluate such a relationship.

\subsection{The role of a condensable organic vapour}

In an additional simulation with the MAFOR model, the role of a semi-volatile organic vapour (OV) in the growth of nucleation mode particles was studied. The formation mechanism of the 
condensable $\mathrm{OV}$ is highly uncertain; it might be directly emitted from the water surface or formed in the atmospheric oxidation of a volatile precursor. Therefore the gas phase OV concentration was prescribed to the model calculation and was kept constant during the simulations. The nucleation mode was initialized with 250 particles $\mathrm{cm}^{-3}$ at a modal diameter of $6 \mathrm{~nm}$ to represent remaining particles from a preceding nucleation event. All other modes were initialized in the same way as summarized in Table 3. The combined nucleation option was used. Wet scavenging depleted numbers of Aitken and accumulation mode particles in the first $7 \mathrm{~h}$ of the simulation.

The presence of OV in the simulation of Arctic aerosol enhances the growth of nucleation mode particles compared to a simulation with no condensing OV (Fig. 10). Condensation of the $\mathrm{OV}$ to the existing Aitken and accumulation mode particles occurs at the same time and leads to a shift of Aitken and accumulation mode particles to larger diameters, eventually to sizes where these become $\mathrm{CCN}$. For the prescribed OV concentration of $30 \times 10^{7} \mathrm{~cm}^{-3}$ (ca. $11 \mathrm{pptv}$ ), the condensation sink dropped from $6.5 \times 10^{-3} \mathrm{~s}^{-1}$ at the start of the simulation to $3.6 \times$ $10^{-3} \mathrm{~s}^{-1}$ after $7 \mathrm{~h}$ and afterwards increased continuously up to $4.5 \times 10^{-3} \mathrm{~s}^{-1}$ at the end of the simulation. Due to the growth of the Aitken mode particles, the coagulation sink increased slightly (from $1.8 \times 10^{-3} \mathrm{~s}^{-1}$ to $2.1 \times 10^{-3} \mathrm{~s}^{-1}$ ) and coagulation of the nucleated particles to the Aitken mode particles increased during the simulation.

Growth of nucleation mode particles by condensation of $\mathrm{OV}$ assisted in the formation of a new number peak (mode) in the diameter range between $8 \mathrm{~nm}$ and $20 \mathrm{~nm}$. The new mode vanished after about $30 \mathrm{~h}$ due to the scavenging of particles to the preexisting Aitken and accumulation mode particles (Figs. 10b-d). Some particles from the new mode could grow further by condensation of $\mathrm{OV}$ and reached sizes of the pre-existing Aitken mode (at OV concentrations $>20 \times 10^{7} \mathrm{~cm}^{-3}$ ). However, we note that the freshly nucleated stable clusters of $1-2 \mathrm{~nm}$ diameter sizes did not grow to detectable sizes $>3 \mathrm{~nm}$ during the simulations. For 1-2 $\mathrm{nm}$ clusters the Kelvin effect imposes a huge barrier and thus clusters can initially probably only grow
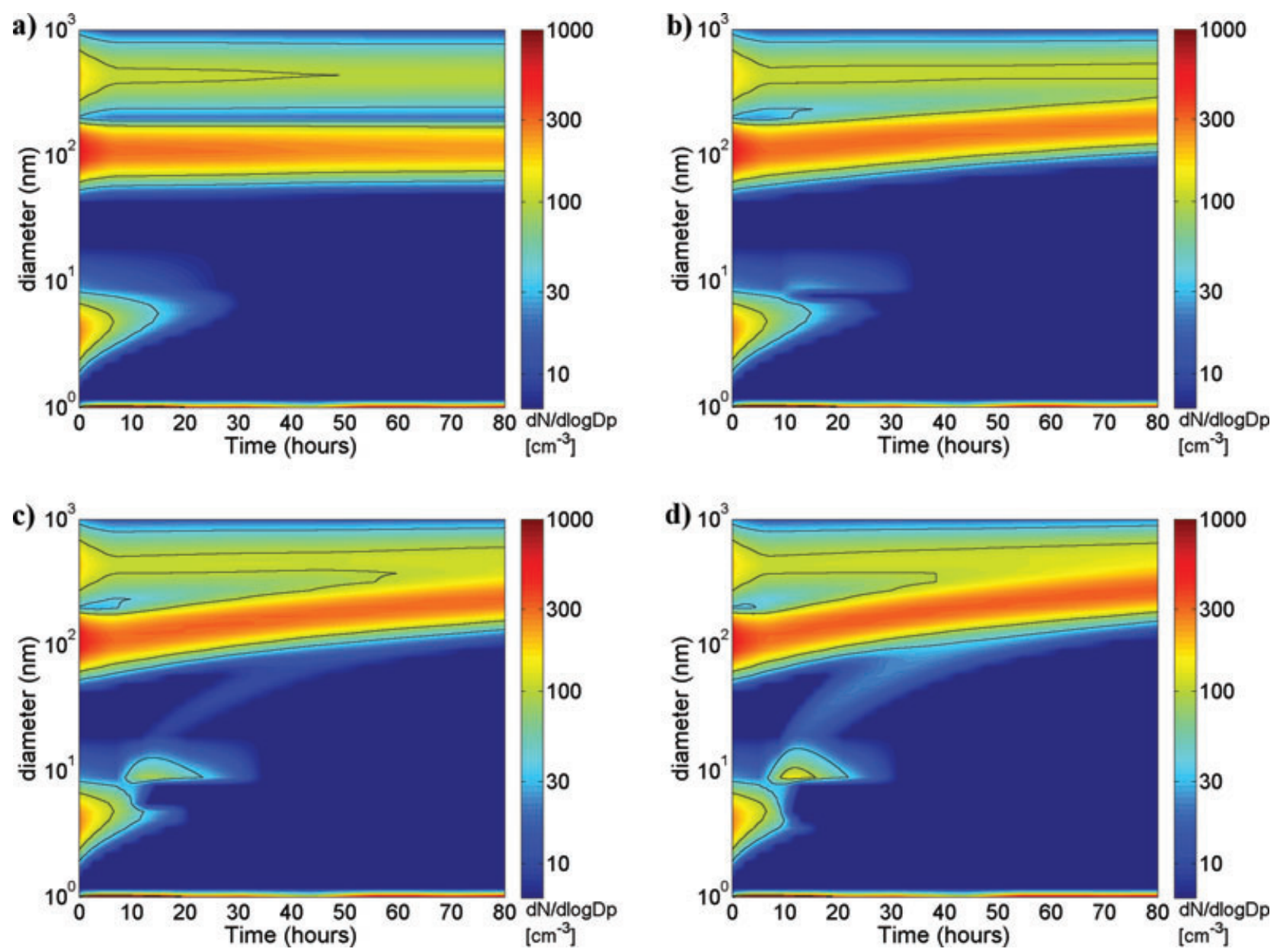

Fig. 10. Growth of nucleation mode particles by condensation of organic vapour (OV) with MAFOR during the simulation of the marine transport scenario: (a) no OV, (b) with OV concentration of $20 \times 10^{7} \mathrm{~cm}^{-3}$, (c) with OV concentration of $30 \times 10^{7} \mathrm{~cm}^{-3}$, (d) with OV concentration of $40 \times$ $10^{7} \mathrm{~cm}^{-3}$. 
by condensation of a non-volatile or extremely low volatile compound.

The case study shows that a condensing organic vapour is required for the growth of nucleation mode particles to CCN sizes. Nucleation mode particles are rapidly lost by dry deposition and by coagulation scavenging to the pre-existing larger particles. It is questionable whether concentration levels of the condensable organic vapour of 7-15 pptv that have been prescribed in these simulations are realistic over the MIZ of the central Arctic Ocean.

Hydrocarbons of anthropogenic origin were reported to decrease in concentration with increasing latitude over the Atlantic and Arctic oceans (Hopkins et al., 2002). Phytoplankton in the oceans are known to produce a large variety of volatile organic compounds, among others isoprene (Shaw et al., 2003). Plankton emissions of isoprene have been suggested to play a dominant role in the formation of secondary organic aerosol (SOA) over tropical oceanic regions (Meskhidze and Nenes, 2006; Gantt et al., 2009). Global emissions of isoprene from the oceans are estimated from in situ observations (e.g. Bonsang et al., 1992) and satellite observations (Palmer and Shaw, 2005) to range from 0.1 to $1.2 \mathrm{Tg} \mathrm{C} \mathrm{yr}^{-1}$. Based on the estimated emission range and a mass-based yield of $2 \%$ SOA from isoprene oxidation (Henze and Seinfeld, 2006), oceanic isoprene appears to be an insignificant source of particulate organic matter in the remote marine atmosphere (Arnold et al., 2009). Hopkins et al. (2002) found no evidence for increased biogenic hydrocarbon emissions in the marginal ice zone. Rather low summertime median isoprene concentrations of 2 pptv have been reported by Hopkins et al. (2002) for the marine BL of the Norwegian Sea $\left(80^{\circ} \mathrm{N}\right)$. Isoprene concentrations measured onboard the Swedish icebreaker Oden during the Arctic Summer Cloud Ocean Study (ASCOS) expedition in August-September 2008 (Paatero et al., 2009) were between 7 and 13 pptv in the MIZ of the central Arctic Ocean (J. Paatero, unpublished data). The presence of elevated concentrations of condensable vapours from biogenic origin however cannot be excluded a priori. Phytoplankton emissions of monoterpenes (Yassaa et al., 2008) might occur in open water south of the MIZ, for example, in the Greenland Sea or the Barent Sea, and the subsequently formed semi-volatile oxidation products like pinonaldehyde could be transported into the MIZ.

\section{Summary and conclusions}

New particle formation or nucleation is the least understood of the processes determining the dynamics of the aerosol size distribution (Kulmala, 2003). Several nucleation mechanisms and their potential to predict particle formation under Arctic summer conditions are tested in this study. Simulated gas phase concentration of sulphuric acid is low as expected for clean marine air and never exceeded $1.0 \times 10^{6} \mathrm{~cm}^{-3}$. Classical theory of homogeneous binary $\mathrm{H}_{2} \mathrm{SO}_{4}-\mathrm{H}_{2} \mathrm{O}$ (Vehkamäki et al., 2002) and ternary $\mathrm{H}_{2} \mathrm{SO}_{4}-\mathrm{H}_{2} \mathrm{O}-\mathrm{NH}_{3}$ (Merikanto et al., 2007) nucleation clearly fail to predict new particle formation in the Arctic $\left(J_{\text {nucl }}=0 \mathrm{~cm}^{-3} \mathrm{~s}^{-1}\right)$. Three of the investigated nucleation mechanisms are able to predict new particle formation in the Arctic BL: ion-mediated, kinetic sulphuric acid and cluster activation. The most efficient nucleation scheme involving sulphuric acid as nucleating agent assumes a linear dependence of the nucleation rate of $1 \mathrm{~nm}$ particles on sulphuric acid concentration (cluster activation; Kulmala et al., 2006). The nucleation rate computed for activation is about 1-2 orders of magnitude higher than for the kinetic or ion-mediated schemes.

One of the unexpected outcomes of the AOE-96 expedition was, that particles between the collection limit ( $15 \mathrm{~nm}$ diameter) and below $50 \mathrm{~nm}$ diameter collected during enhanced nucleation periods did not contain any sulphuric acid component according to electron microscopy analysis (Leck and Bigg, 1999; subsequently confirmed in Leck and Bigg, 2005a, 2005b). Instead the particles were found to be solid, often crystalline and unaffected by heating with the electron beam. Absence of sulphuric acid in particles between $15 \mathrm{~nm}$ and $50 \mathrm{~nm}$ diameter would be inconsistent with classical binary nucleation and other nucleation mechanisms that involve sulphuric acid, unless substantial amounts of another condensable vapour, likely organic, would condensate on the stabilized clusters or participates in the nucleation process. In this case the initial sulphuric acid cluster or mixed sulphuric acid/organic cluster would be surrounded by one or several layers of (organic) molecules masking the presence of sulphuric acid in the electron microscope analysis.

In the last years, an enormously wide range of organic compounds has been found in polar and remote marine aerosols (Masclet and Hoyau, 1995). Dicarboxylic acids were present in the collected aerosols during AOE-96 in significant amounts. We have chosen one of the detected dicarboxylic acids, succinic acid, in our model study as condensing vapour to assist in the growth of nucleation mode particles. The growth of nucleation mode particles due to condensation of this OV competes with their loss through dry deposition and coagulation to the pre-existing particle population. Model simulations indicate that growth of ultrafine particles to $\mathrm{CCN}$ sizes under Arctic conditions can only occur in the presence of sufficiently high concentrations of a condensing organic vapour ( $>7 \mathrm{pptv}$ ) in the gas phase.

Freshly nucleated stable clusters of 1-2 nm diameter sizes do not grow to detectable sizes $>3 \mathrm{~nm}$ during the simulations since the Kelvin effect prevents condensation of the organic vapour to the small particles. The presence of a sufficiently low volatility vapour or non-volatile vapour is probably required for the initial growth of stable clusters. In addition, heterogeneous reactions may play a critical role in helping the fresh clusters to overcome the huge Kelvin barrier (Zhang and Wexler, 2002). Choosing an organic compound with different molecular properties, for instance lower saturation vapour pressure, than succinic acid to represent the OV will therefore affect both the concentration required for growth of nucleation mode particles into $\mathrm{CCN}$ sizes 
and the initial growth of nucleated clusters. It was however not in the scope of this study to explore the potential molecular properties of the condensable OV.

Aerosol size distribution and total particle number concentrations calculated by the new sectional aerosol dynamics model MAFOR compared reasonably well with the sectional model AEROFOR. For example, resulting final total number concentrations of $>3 \mathrm{~nm}$ diameter sized particles deviated less than $25 \%$ in the different test simulations.

Modelled concentrations of sulphur-containing compounds in the gas and particulate phase obtained from the new model were in agreement with the widely applied monodisperse aerosol model MONO32. DMS decay during advection of an air parcel from the DMS source region at the marginal ice edge over the pack ice was captured by all three models and predicted concentrations of $\mathrm{H}_{2} \mathrm{SO}_{4}$ and MSA in the gas phase ranged up to $1.0 \times$ $10^{6} \mathrm{~cm}^{-3}$ and $1.8 \times 10^{6} \mathrm{~cm}^{-3}$, respectively. Predicted concentration of $\mathrm{H}_{2} \mathrm{SO}_{4}$ and MSA were shown to be highly sensitive to the exact value of the $\mathrm{CH}_{3} \mathrm{SO}_{2}$ thermal decomposition rate constant.

Uncertainties of modelled $\mathrm{H}_{2} \mathrm{SO}_{4}$ gas phase concentration is propagated into modelled numbers of newly formed particles. Variation of initial $\mathrm{O}_{3}$ and DMS concentrations in the marine transport scenario simulation by \pm 5 ppbv and \pm 50 pptv results in an uncertainty of $20 \%$ and $21 \%$, respectively, for the modelled number concentrations of newly formed particles. There is urgent need for measurements of $\mathrm{H}_{2} \mathrm{SO}_{4}$ and MSA gas phase concentrations in the summer Arctic BL to better constrain their availability for nucleation and condensation processes in the aerosol models.

The newly developed sectional aerosol model MAFOR performs well under summer Arctic conditions which are characterized by low abundance of pre-existing particles and sudden changes of the aerosol size distribution. For more general application of the model in marine aerosol modelling, the implementation of a primary marine source (e.g. a combined organic-inorganic sea spray function) and an improved treatment of the thermodynamic condensation of water and the liquid-solid phase transformation of sulphur compounds in aerosol droplets are envisaged.

\section{Acknowledgments}

This work was in part funded by the Swedish Research Council, the International Institute of Meteorology and the Knut and Alice Wallenberg Foundation. The Swedish Polar Research Secretariat provided access to the icebreaker Oden and logistical support. We are grateful to Oden's Captain Anders Backman and his crew. The development of the aerosol model was in part funded from Statoil ASA, Vattenfall, Masdar and Gassnova through CLIMIT projects 193438 and 201604 (http://www.climit.no). We thank Hanna Vehkamäki for providing the new ternary nucleation parameterization, Veli-Matti Kerminen and Markku Kulmala for discussion of aspects of nucleation and condensation, Gunilla Svensson and Michael Tjernström for initial discussions on the marine transport scenario. Kari E. J. Lehtinen is thanked for inspiration to begin this model development.

\section{References}

Asmi, E., Frey, A., Virkkula, A., Ehn, M., Manninen, H. E. and coauthors. 2009. Hygroscopicity and chemical composition of Antarctic sub-micrometre aerosol particles and observations of new particle formation. Atmos. Chem. Phys. Discuss. 9, 27303-27357.

Anttila, T. H., Vehkamki, H., Napari, I. and Kulmala, M. 2005. Effect of ammonium bisulfate formation on atmospheric water-sulfuric acidammonia nucleation. Boreal Environ. Res. 10, 511-523.

Arnold, S. R., Spracklen, D. V., Williams, J., Yassaa, N., Sciare, J. and co-authors. 2009. Evaluation of the global oceanic isoprene source and its impacts on marine organic carbon aerosol. Atmos. Chem. Phys. 9, 1253-1262.

Atkinson, R., Baulch, D. L., Cox, R. A., Crowley, J. N., Hampson, R. F. Jr. and co-authors. 2004. Summary of Evaluated Kinetic and Photochemical Data for Atmospheric Chemistry, IUPAC Subcommittee on Gas Kinetic Data Evaluation for Atmospheric Chemistry. Available at: http://www.iupac-kinetic.ch.cam.ac.uk. Accessed on 23-March-2011.

Bardouki, H., Berresheim, H., Vrekoussis, M., Sciare, J., Kouvarakis, G. and co-authors. 2003. Gaseous (DMS, MSA, SO $\mathrm{S}_{2}, \mathrm{H}_{2} \mathrm{SO}_{4}$ and DMSO) and particulate (sulfate and methanesulfonate) sulfur species over the northeastern coast of Crete. Atmos. Chem. Phys. 3, 1871-1886.

Bazilevskaya, G. A., Usoskin, I. G., Flückiger, E. O., Harrison, R. G., Desorgher, L. and co-authors. 2008. Cosmic ray induced ion production in the atmosphere. Space Sci. Rev. 137, doi10.1007/s11214-0089339-y.

Bates, T., Kapustin, V., Quinn, P., Covert, D., Coffman, D. and coauthors. 1998. Processes controlling the distribution of aerosol particles in the lower marine boundary layer during the First Aerosol Characterization Experiment (ACE 1). J. Geophys. Res. 103(D13), 16369-16383.

Bigg, E. K., Leck, C. and Nilsson, E. D. 1996. Sudden changes in arctic atmospheric aerosol concentrations during summer and autumn. Tellus 48B, 254-271.

Bigg, E. K., Leck, C. and Nilsson, E. D. 2001. Sudden changes in aerosol and gas concentrations in the central Arctic marine boundary layer - Causes and consequences. J. Geophys. Res. 106(D23), 32 16732185 .

Bilde, M., Svenningsson, B., Mønster, J., and Rosenørn, T. 2003. Evenodd alternation of evaporation rates and vapor pressures of C3-C9 dicarboxylic acid aerosols. Environ. Sci. Technol. 37, 1371-1378.

Bonsang, B., Polle, C. and Lambert, G. 1992. Evidence for marine production of isoprene. Geophys. Res. Lett. 19, 1129-1132.

Charlson, R. J., Lovelock, J. E., Andreae, M. O. and Warren, S. G. 1987. Oceanic phytoplankton, atmospheric sulphur, cloud albedo and climate. Nature 326, 655-661.

Clarke, A. D, Davis, D., Kapustin, V. N., Eisele, F., Chen, G. and coauthors. 1998. Particle nucleation in the tropical boundary layer and its coupling to marine sulfur sources. Science 282, 89-91.

Covert, D. S., Wiedensohler, A., Aalto, P., Heintzenberg, J., McMurry, P. H. and co-authors. 1996. Aerosol number distribution from 3 to 
$500 \mathrm{~nm}$ diameter in the arctic marine boundary layer during summer and autumn Tellus 48B, 197-212.

Davis, D. D., Chen, G., Kasibhatla, P., Jefferson, A., Tanner, D. and coauthors. 1998. DMS oxidation in the Antarctic marine boundary layer: comparison of model simulations and field observations of DMS, DMSO, $\mathrm{DMSO}_{2}, \mathrm{H}_{2} \mathrm{SO}_{4}(\mathrm{~g})$, MSA(g), and MSA(p). J. Geophys. Res. 103(D1), 1657-1678.

De Bruyn, W. J., Shorter, J. A., Davidovits, P., Worsnop, D. R., Zahniser, M. S., and co-authors. 1994. Uptake of gas phase sulfur species methanesulfonic acid, dimethylsulfoxide, and dimethyl sulfone by aqueous surfaces. J. Geophys., Res. 99, 16937-16932.

Dhaniyala, S. and Wexler, A. S. 1996. Numerical schemes to model condensation and evaporation of aerosols. Atmos. Environ. 30, 919-928.

EL CID 2003. Evaluation of the Climatic Impact of Dimethyl Sulphide, Final report of the EC 5FP project: evaluation of the Climate Impact of Dimethyl Sulphide (EL CID), Project coordinator Prof. Barnes, I., Contract number: EVK2-CT-1999-00033.

Ervens, B., Carlton, A. G., Turpin, B. J., Altieri, K. E., Kreidenweis, S. M., andco-authors. 2008. Secondary organic aerosol yields from cloud-processing of isoprene oxidation products. Geophys. Res. Lett. 35, L02816, doi:10.1029/2007GL031828.

Ferek, R. J., Hobbs, P. V., Radke, L. F., Herring, J. A., Sturges, W. T. andco-authors. 1995. Dimethyl sulfide in the arctic atmosphere. J. Geophys. Res. 100(D12), 26093-26104.

Finlayson-Pitts, B. J. and Pitts, J. N. Jr. 1986. Atmospheric Chemistry: Fundamentals and Experimental Techniques. Wiley, Chichester.

Fuchs, N. A. 1964. The Mechanics of Aerosols. Pergamon, New York.

Fuchs, N. A. and Sutugin, A. G. 1970. Highly Dispersed Aerosols. Ann. Arbor Sci., Ann Arbor, MI.

Gantt, B., Meskhidze, N. and Kamykowski, D. 2009. A new physicallybased quantification of marine isoprene and primary organic aerosol emissions. Atmos. Chem. Phys. 9, 4915-4927.

Gelbard, F. 1990. Modeling multicomponent aerosol particle growth by vapor condensation. Aerosol Sci. Technol. 12, 399-412.

Gelbard, F. and Seinfeld, J. H. 1980. Simulation of multicomponent aerosol dynamics. J. Colloid Interface Sci. 78, 541-556.

Gong, S. L., Walmsley, J. L., Barrie, L. A. and Hopper, J. F. 1997. Mechanisms for surface ozone depletion and recovery during the Polar Sunrise. Atmos. Environ. 6(14), 969-981.

Hatakeyama, S., Izumi, K. and Akimoto, H. 1985. Yield of $\mathrm{SO}_{2}$ and formation of aerosol in the photo-oxidation of DMS under atmospheric conditions. Atmos. Environ. 19, 83-586.

Heintzenberg, J. and Leck, C. 1994. Seasonal variations of the atmospheric aerosol near the top of the marine boundary layer over Spitsbergen related to the Arctic sulfur cycle. Tellus 46B, 52-67.

Heintzenberg, J., Birmili, W., Wiedensohler, A., Nowak, A. and Tuch, T. 2004. Structure, variability and persistence of the submicrometre marine aerosol. Tellus 56B, 357-367.

Heintzenberg, J., Leck, C., Birmili, W., Wehner, B., Tjernström, M. and co-authors. 2006. Aerosol number-size distributions during clear and fog periods in the summer high Arctic 1991, 1996 and 2001. Tellus 58B, 341-359.

Hensen, A. and van der Hage, J. C. H. 1994. Parameterization of cosmic radiation at sea level. J. Geophys. Res. 99(D5), 10 693-10 695.

Henze, D. K. and Seinfeld, J. H. 2006. Global secondary organic aerosol from isoprene oxidation. Geophys. Res. Lett. 33, L09812, doi:10.1029/2006GL025976.
Hopkins, J. R., Jones, I. D., Lewis, A. C., McQuaid, J. B. and Seakins, P. W. 2002. Non-methane hydrocarbons in the Arctic boundary layer. Atmos. Environ. 36, 3217-3229.

Hoppel, W. A. 1987. Nucleation in the MSA-water vapor system. Atmos. Environ. 6(14), 2703-2709.

Hoppel, W. A., Frick, G. M., Fitzgerald, J. W. and Larson, R. E. 1994. Marine boundary layer measurements of new particle formation and the effects nonprecipitating clouds have on the aerosol size distribution. J. Geophys. Res. 99, 14443-14459.

Hõrrak, U., Salm, J. and Tammet, H. 1998. Bursts of intermediate ions in atmospheric air. J. Geophys. Res. 103, 13 909-13 915.

Hyvärinen, A.-P., Lihavainen, H., Gaman, A., Vairila, L., Ojala, H. and co-authors. 2006. Surface tensions and densities of oxalic, malonic, succinic, maleic, malic, and cis-pinonic acids. J. Chem. Eng. Data 51, 255-260.

IPCC 2007. Intergovernmental Panel on Climate Change 2007, Fourth Assessment Report - The physical science basis. Cambridge University Press, Cambridge, UK and New York, NY, USA.

Jacobson, M. C., Hansson, H.-C., Noone, K. J. and Charlson, R. J. 2000. Organic atmospheric aerosols: review and state of the science. Rev. Geophys. 38, 267-294.

Jacobson, M. Z. 1997. Development and application of a new air pollution modeling system - II. Aerosol module structure and design. Atmos. Environ. 31, 131-144.

Jacobson, M. Z. 2005. Fundamentals of Atmospheric Modeling, Second Edition. Cambridge University Press, Cambridge.

Jacobson, M. Z. and Turco, R. P. 1995. Simulating condensational growth, evaporation, and coagulation of aerosols using a combined moving and stationary size grid. Aerosol Sci. Technol. 22, 73-92.

Jaecker-Voirol, A., Mirabel, P. and Reiss, H. 1987. Hydrates in supersaturated binary sulfuric acid-water vapor: a reexamination. J. Chem. Phys. 87, 4849-4852.

Jefferson, A., Tanner, D. J., Eisele, F. L., Davis, D. D., Chen, G. and coauthors. 1998. OH photochemistry and methane sulfonic acid formation in the coastal Antarctic boundary layer. J. Geophys. Res. 103(D1), 1647-1656.98.

Karl, M., Gross, A., Leck, C. and Pirjola, L. 2007. Intercomparison of dimethylsulfide oxidation mechanisms for the marine boundary layer: gaseous and particulate sulfur constituents. J. Geophys. Res. 112, D15304, doi:10.1029/2006JD007914.

Kawamura, K. and Usukura, K. 1993 Distribution of low molecular weight dicarboxylic acids in the north pacific aerosol samples. J. Oceanography 49, 271-283.

Kawamura, K., Kasukabe, H. and Barrie, L. A. 1996. Source and reaction pathways of dicarboxylic acids, ketoacids and dicarbonyls in arctic aerosols at polar sunrise. Atm. Environ. 30, 1709-1722.

Kerminen, V.-M. and Leck, C. 2001. Sulfur chemistry over the central Arctic Ocean in summer: gas to particle transformation. J. Geophys. Res. 106, 32 087-32099.

Kokkola, H., Korhonen, H., Lehtinen, K. E. J., Makkonen, R., Asmi, A. and co-authors. 2008. SALSA - a Sectional Aerosol module for Large Scale Applications. Atmos. Chem. Phys. 8, 2469-2483.

Korhonen, P., Kulmala, M., Laaksonen, A., Viisanen, Y., McGraw, R. and co-authors. 1999. Ternary nucleation of $\mathrm{H}_{2} \mathrm{SO}_{4}, \mathrm{NH}_{3}$, and $\mathrm{H}_{2} \mathrm{O}$ in the atmosphere. J. Geophys. Res. 104, 26349-26353.

Korhonen, H., Lehtinen, K. E. J., Pirjola, L., Napari, I., Vehkamäki, H. and co-authors. 2003. Simulation of atmospheric nucleation mode: a 
comparison of nucleation models and size distribution representations. J. Geophys. Res. 108(D15), 4471, doi:10.1029/2002JD003305.

Korhonen, H., Lehtinen, K. E. J., and Kulmala, M. 2004. Multicomponent aerosol dynamics model UHMA: model development and validation. Atmos. Chem. Phys. 4, 757-771.

Kreidenweis, S. M. and Seinfeld, J. H. 1988a. Nucleation of sulfuric acid-water and methanesulfonic acid-water solution particles: implications for the atmospheric chemistry of organosulfur species. Atm. Environ. 22(2), 283-296.

Kreidenweis, S. M. and Seinfeld, J. H. 1988b. Effect of surface tension of aqueous methanesulfonic acid solutions upon nucleation and growth of aerosol. Atm. Environ. 6(14), 1499-1500.

Kreidenweis, S. M., Penner, J. E., Yin, F. and Seinfeld, J. H. 1991. The effects of dimethylsulfide upon marine aerosol concentrations. Atm. Environ. 6(14), 2501-2511.

Kulmala, M. 2003. How particles nucleate and grow. Science 302, 1000-1001.

Kulmala, M. and Laaksonen, A. 1990. Binary nucleation of watersulfuric acid system: comparison of classical theories with different $\mathrm{H}_{2} \mathrm{SO}_{4}$ saturation vapor pressures. J. Chem. Phys. 93, 696-701.

Kulmala, M., Laaksonen, A. and Pirjola, L. 1998. Parameterizations for sulfuric acid/water nucleation rates. J. Geophys. Res. 103, 83018307.

Kulmala, M., Pirjola, L. and Mäkelä, J. M. 2000. Stable sulphate clusters as a source of new atmospheric particles. Nature 404, 66-69.

Kulmala, M., Vehkamäki, H., Petäjä, T., Dal Maso, M., Lauri, A. and coauthors. 2004a. Formation and growth rates of ultrafine atmospheric particles: a review of observations. J. Aerosol Sci. 35, 143-176.

Kulmala, M., Kerminen, V.-M., Anttila, T., Laaksonen, A. and O'Dowd, D. 2004b. Organic aerosol formation via sulphate cluster activation. J. Geophys. Res. 109, D04205, doi:10.1029/2003JD003961.

Kulmala, M., Lehtinen, K. E. J., and Laaksonen, A. 2006. Cluster activation theory as an explanation of the linear dependence between formation rate of $3 \mathrm{~nm}$ particles and sulphuric acid concentration. Atmos. Chem. Phys. 6, 787-793.

Kulmala, M., Riipinen, I., Sipilä, M., Manninen, H. E., Petäjä, T. and coauthors. 2007. Toward direct measurement of atmospheric nucleation. Science 318, 89-92.

Laakso, L., Anttila, T., Lehtinen, K. E. J., Aalto, P .P., Kulmala, M. and co-authors. 2004. Kinetic nucleation of ions in boreal forest particle formation events. Atmos. Chem. Phys. 4, 2353-2366.

Landgraf, J. and Crutzen, P. J. 1998. An efficient method for online calculations of photolysis and heating rates. J. Atm. Sci. 55, 863878.

Lannefors, H., Heintzenberg, J. and Hansson, H.-C. 1983. A comprehensive study of physical and chemical parameters of the Arctic summer aerosol; results from the Swedish expedition Ymer-80. Tellus 35B, $40-54$.

Leck, C. and Persson, C. 1996a. The central Arctic as a source of DMS: seasonal variability in relation to biological activity. Tellus 48B, 156-177.

Leck, C. and Persson, C. 1996b. Seasonal and short-term variability in dimethylsulfide, sulfur dioxide and biogenic sulfur and sea salt aerosol particles in the Arctic marine boundary layer during summer and autumn. Tellus 48B, 272-299.

Leck, C. and Bigg, E. K. 1999. Aerosol production over remote marine areas. - A new route. J. Geophys. Res. 26, 3577-3580.
Leck, C. and Bigg, E. K. 2005a. Biogenic particles in the surface microlayer and overlaying atmosphere in the central Arctic Ocean during summer. Tellus 57B, 305-316.

Leck, C. and Bigg, E. K. 2005b. Evolution of the marine aerosol. A new perspective. Geophys. Res. Lett. 32, L19803, doi:10, 1029/2005GL023651.

Leck, C. and Bigg, E. K. 2010. New particle formation of marine biological origin. Aerosol Sci. Tech. 6(14), 570-577.

Leck, C., Bigg, E. K., Covert, D. S., Heintzenberg, J., Maenhaut, W., Nilsson, E. D. and Wiedensohler, A. 1996. Overview of the atmospheric research program during the International Arctic Ocean Expedition 1991 (IAOE-91) and its scientific results. Tellus 48B, 136-155.

Leck, C., Nilsson, E. D., Bigg, E. K. and Bäcklin, L. 2001. Atmospheric program on the Arctic Ocean Expedition 1996 (AOE-96): an overview of scientific goals, experimental approach, and instruments. J. Geophys. Res. 106(D23), 32 051-32067.

Leck, C., Norman, M., Bigg, E. K. and Hillamo, R. 2002. Chemical composition and sources of the high Arctic aerosol relevant for cloud formation, J. Geophys. Res. 107(D12), doi:10.1029/2001JD001463.

Loeb, L. B. 1960. Basic Processes of Gaseous Electronics. Chapter VI. Univ. of Calif. Press, Berkeley.

Lohmann, U. and Leck, C. 2005. Importance of submicron surface-active organic aerosols for pristine Arctic clouds. Tellus 57B, 261-268.

Lushnikov, A. A. and Kulmala, M. 1998. Dimers in nucleating vapors. Phys. Rev. E 58(3), 3157-3167.

Masclet, P. and Hoyau, V. 1995. Speciation of particulate organic matter in arctic aerosols. J. Aerosol Sci. 26, S437.

Mauldin, R. L., Eisele, F. L., Tanner, D. J., Kosciuch, E., Shetter, R. and co-authors. 2001. Measurements of $\mathrm{OH}, \mathrm{H}_{2} \mathrm{SO}_{4}$, and MSA at the South Pole during ISCAT. Geophys. Res. Lett. 28, 3629-3632.

McGrath, R. 1989. Trajectory models and their use in the Irish Meteorological Service. Memo. 112/89. Irish Meteorol. Serv., Dublin.

Mellouki, A., Jourdain, J. L. and Le Bras, G., 1988. Discharge flow study of the $\mathrm{CH}_{3} \mathrm{~S}+\mathrm{NO}_{2}$ reaction mechanism using $\mathrm{Cl}+\mathrm{CH}_{3} \mathrm{SH}$ as the $\mathrm{CH}_{3} \mathrm{~S}$ source. Chem. Phys. Lett. 148(2,3), 231-236.

Merikanto, J., Napari, I., Vehkamäki, H., Anttila, T. and Kulmala, M. 2007. New parameterization of sulfuric acid-ammonia-water ternary nucleation rates at tropospheric conditions. J. Geophys. Res. 112 D15207, doi:10.1029/2006JD007977.

Mochida, M., Umemoto, N., Kawamura, K. and Uematsu, M. 2003. Bimodal size distribution of C2-C4 dicarboxylic acids in the marine aerosols. Geophys. Res. Lett. 30(13), 1672, doi:10.1029/2003GL017451.

Meskhidze, N. and Nenes, A. 2006. Phytoplankton and cloudiness in the Southern Ocean. Science 317, 1419, doi:10.1126/science.1131779.

Modini, R. L., Ristovski, Z. D., Johnson, G. R., He, C., Surawski, N. and co-authors. 2009. New particle formation and growth at a remote, sub-tropical coastal location. Atmos. Chem. Phys. 9, 7607-7621.

Napari, I., Noppel, M., Vehkamäki, H., and Kulmala, M. 2002a. An improved model for ternary nucleation of sulfuric acid-ammoniawater. J. Chem. Phys. 116, 4221-4227.

Napari, I., Noppel, M., Vehkamäki, H. and Kulmala, M. 2002b. Parameterization of ternary nucleation rates for $\mathrm{H}_{2} \mathrm{SO}_{4}-\mathrm{NH}_{3}-\mathrm{H}_{2} \mathrm{O}$ vapors. J. Geophys. Res. 107(D19), 4381, doi:10.1029/2002JD002131.

Nguyen, K. and Dabdub, D. 2002. Semi-Lagrangian flux scheme for the solution of the aerosol condensation/evaporation equation. Aerosol Sci. Technol. 36, 407-418. 
Nilsson, E. D. and Barr, S. 2001. Effects of synoptic patterns on atmospheric chemistry and aerosols during the Arctic Ocean Expedition 1996. J. Geophys. Res. 106, 32 069-32086.

Nilsson, E. D. and Leck, C. 2002. A pseudo-Lagrangian study of the arctic remote marine sulfur cycle. Tellus 54B, 213-230.

Noppel, M., Vehkamäki, H. and Kulmala, M. 2002. An improved model for hydrate formation in sulfuric acid-water nucleation. J. Chem. Phys. 116, 218-228.

O’Dowd, C. D., Davison, B., Lowe, J. A., Smith, M. H., Harrison, R. M., andco-authors. 1997. Biogenic sulphur emissions and inferred sulphate CCN concentrations in and around Antarctica. J. Geophys. Res. 102, 12 839-12854.

O’Dowd, C. D., Geever, M., Hill, M. K., Smith, M. H. and Jennings, S. G. 1998. New particle formation: nucleation rates and spatial scales in the clean marine coastal environment. Geophys. Res. Lett. 6(14), $1661-1664$.

O’Dowd, C. D., McFiggans, G., Creasey, D. J., Pirjola, L., Hoell, C. and co-authors. 1999. On the photochemical production of new particles in the coastal boundary layer. Geophys. Res. Lett. 26(12), 1707-1710.

O’Dowd, C. D., Jimenez, J. L., Bahreini, R., Flagan, R. C., Seinfeld, J. H. and co-authors. 2002. Marine aerosol formation from biogenic iodine emissions. Nature 417, 632-636, doi:10.1038/nature00775.

Paatero, J., Vaattovaara, P., Vestenius, M., Meinander, O., Makkonen, U. and co-authors. 2009. Finnish contribution to the Arctic Summer Cloud Ocean Study (ASCOS) expedition, Arctic Ocean 2008. Geophysica 45(1-2), 119-146.

Palmer, P. I. and Shaw, S. L. 2005. Quantifying global marine isoprene fluxes using MODIS chlorophyll observations. Geophys. Res. Lett. 32, L09805, doi:10.1029/2005GL022592.

Pechtl, S., Lovejoy, E. R., Burkholder, J. B. and von Glasow, R. 2006. Modeling the possible role of iodine oxides in atmospheric new particle formation. Atmos. Chem. Phys. 6, 505-523.

Penner, J. E., Andreae, M., Annegarn, H., Barrie, L., Feichter, J. and coauthors. 2001. Aerosols, their direct and indirect effects. In: Climate Change 2001: The Scientific Basis, Working Group I contribution to the IPCC Third Assessment report: Summary for policymakers, 289-348.

Pirjola, L. 1999. Effects of the increased UV radiation and biogenic VOC emissions on ultrafine sulphate aerosol formation. J. Aerosol Sci. 30, 355-367.

Pirjola, L. and Kulmala, M. 2000. Aerosol dynamical model MULTIMONO. Boreal Environ. Res. 5, 361-374.

Pirjola, L. and Kulmala, M. 2001. Development of particle size and composition distributions with a novel aerosol dynamics model. Tellus 53B, 491-509.

Pirjola, L., Laaksonen, A., Aalto, P. and Kulmala, M. 1998. Sulphate aerosol formation in the Arctic boundary layer. J. Geophys. Res. 103, 8309-8322.

Pirjola, L., Kulmala, M., Wilck, M., Bischoff, A., Stratmann, F. and co-authors. 1999a. Effects of aerosol dynamics on the formation of sulphuric acid aerosols and cloud condensation nuclei. J. Aerosol Sci. 30, 1079-1094.

Pirjola, L., Boy, M., Kulmala, M. and Kerminen, V.-M. 1999b. Interaction between $\mathrm{SO}_{2}$ and submicron atmospheric aerosols. J. Aerosol Sci. 30(Suppl. 1), 249-250.

Pirjola, L., O'Dowd, C. D. and Kulmala, M. 2002. A model prediction of the yield of cloud condensation nuclei from coastal nucleation events. J. Geophys. Res. 107(D19), 8098, doi:10.1029/2000JD000213.

Pirjola, L., Tsyro, S., Tarrasòn, L. and Kulmala, M. 2003. A monodisperse aerosol dynamics module, a promising candidate for use in long-range transport models: box model tests. J. Geophys. Res. 108, D9, 4258, doi:10.1029/2002JD002867.

Pirjola, L., Lehtinen, K. E. J., Hansson, H.-C. and Kulmala, M. 2004. How important is nucleation in regional/global modelling?. Geophys. Res. Lett. 31, L12109, doi:10.1029/2004GL019525.

Pirjola, L., O’Dowd, C. D., Yoon, Y. J. and Sellegri, K. 2005. Modelling iodine particle formation and growth from seaweed in a chamber. Environ. Chem. 2, 271-281, doi:10.1071/EN05075.

Pruppacher, H. R. and Klett, J. D. 1978. Microphysics of clouds and precipitation. D. Reidel, Norwell, MA.

Raes, F. 1995. Entrainment of free tropospheric aerosols as a regulating mechanism for cloud condensation nuclei in the remote marine boundary layer. J. Geophys. Res. 100, 2893-2903.

Raes, F., Janssens, A., and van Dingenen, R. 1986. The role of ioninduced aerosol formation in the lower atmosphere. J. Aerosol. Sci. 17, 466-470, doi:10.1016/0021-8502(86)90135-7.

Raes, F., van Dingenen, R., Vignati, E., Wilson, J., Putaud, J.-P. and co-authors. 2000. Formation and cycling of aerosols in the global troposphere. Atmos. Environ. 34, 4215-4240.

Reiter, R. 1992. Phenomena in Atmospheric and Environmental Electricity. Elsevier, New York.

Riipinen, I., Sihto, S.-L., Kulmala, M., Arnold, F., Dal Maso, M. and coauthors. 2007. Connections between atmospheric sulphuric acid and new particle formation during QUEST III-IV campaigns in Heidelberg and Hyytiälä. Atmos. Chem. Phys. 7, 1899-1914.

Roeckner, E., Bäuml, G., Bonaventura, L., Brokopf, R., Esch, M. and coauthors. 2003. The atmospheric general circulation model ECHAM5. Part I: Model description, MPI-Report, $127 \mathrm{pp}$.

Saiz-Lopez, A., Plane, J. M. C., McFiggans, G., Williams, P. J., Ball, S. M. and co-authors. 2006. Modelling molecular iodine emissions in a coastal environment: the link to new particle formation. Atmos. Chem. Phys. 6, 883-895.

Saltelli, A. and Hjorth, J., 1995. Uncertainty and sensitivity analyses of OH-initiated dimethyl sulphide (DMS) oxidation kinetics. J. Atmos. Chem. 21, 187-221.

Sander, R. and Crutzen, P. J. 1996. Model study indicating halogen activation and ozone destruction in polluted air masses transported to the sea. J. Geophys. Res. 101, 9121-9138.

Sander, R., Kerkweg, A., Jöckel, P. and Lelieveld, J. 2005. Technical note: the new comprehensive atmospheric chemistry module MECCA. Atmos. Chem. Phys. 5, 445-450.

Sander, S. P., Friedl, R. R., Ravishankara, A. R., Golden, D. M., Kolb, C. E. and co-authors. 2003. Chemical Kinetics and Photochemical Data for Use in Atmospheric studies, Evaluation No. 14, JPL Publication $02-25$.

Sandu, A., Verwer, J. G., Blom, J. G., Spee, E. J., Carmichael, G. R. and co-authors. 1997. Benchmarking stiff ODE solvers for atmospheric chemistry problems II. Rosenbrock solvers. Atmos. Environ. 31, 43459-3472.

Schack Jr., C. J., Pratsinis, S. E. and Friedlander, S. K. 1986. A general correlation for deposition of suspended particles from turbulent gases to completely rough surfaces. Atmos. Environ. 19, 953960. 
Schwartz, S. E. 1986. Mass transport considerations pertinent to aqueous phase reactions of gases in liquid water clouds. In: Chemistry of Multiphase Atmospheric Systems, NATO ASI Series, Vol. 6, (ed. W. Jaeschke), Springer, Berlin, 415-471.

Shaw, G. E. 1989. Production of condensation nuclei in clean air by nucleation of $\mathrm{H}_{2} \mathrm{SO}_{4}$. Atmos. Environ. 23, 2841-2846.

Shaw, S. L., Chisholm, S. W., and Prinn, R. G. 2003. Isoprene production by Prochlorococcus, a marine cyanobacterium, and other phytoplankton. Mar. Chem. 80, 227-245.

Simpson, D. 1992. Long-period modelling of photochemical oxidants in Europe. Model calculation for July 1985. Atmos. Environ. 26A, 1609-1634.

Stockwell, W. R., Kirchner, F., Kuhn, M., and Seefeld, S. 1997. A new mechanism for regional atmospheric chemistry modeling. J. Geophys. Res. 102, $25847-25879$.

Ström, J., Engvall, A.-C., Delbart, F., Krejci, R., and Treffeisen, R. 2009. On small particles in the Arctic summer boundary layer: observations at two different heights near Ny-lesund, Svalbard.Tellus 62B, doi:10.1111/j.1600-0889.2008.00412.x.

Tang, I. N. and Munkelwitz, H. R. 1994. Water activities, densities, and refractive indices of aqueous sulphates and sodium nitrate droplets of atmospheric importance. J. Geophys. Res. 99, 1880118808.

Tilgner, A., Wolke, R., and Herrmann, H. 2008. CAPRAM modeling of the physicochemical cloud processing of tropospheric aerosols, in Environmental simulation chambers. Application to atmospheric chemical processes. In: Proceedings of the NATO Advanced Research Workshop on Simulation and Assessment of Chemical Processes in a Multiphase Environment Alushta, Ukraine 1 September 2007, (eds. Barnes, I. and Kharytonov, M.) Springer, Berlin, Heidelberg, New York, 540.

Tsang, T. H. and Rao, A. 1988. Comparison of different numerical schemes for condensational growth of aerosols. Aerosol Sci. Technol. 9, 271-277.

Twomey, S. A. 1974. Pollution and the planetary albedo. Atmos. Environ. 8, 1251-1256.

Van Dingenen, R. and Raes, F. 1993. Ternary nucleation of methane sulphonic acid, sulphuric acid and water vapour. J. Aerosol Sci. 6(14), $1-17$.

Vehkamäki, H., Kulmala, M., Napari, I., Lehtinen, K. E. J., Timmreck, C. and co-authors. 2002. An improved parameterization for sulphuric acid-water nucleation rates for tropospheric and stratospheric conditions. J. Geophys. Res. 107(D22), 4622, doi:10.1029/2002JD002184.
Virkkula, A., Hirsikko, A., Vana, M., Aalto, P. P., Hillamo, R. and co-authors. 2007. Charged particle size distributions and analysis of particle formation events at the Finnish Antarctic research station Aboa. Boreal Environ. Res. 12, 397-408.

Vuollekoski, H., Kerminen, V.-M., Anttila, T., Sihto, S.-L., Vana, M. and co-authors. 2009. Iodine dioxide nucleation simulations in coastal and remote marine environments. J. Geophys. Res. 114, D02206, doi:10.1029/2008JD010713.

Weber, R. J., McMurry, P. H., Eisele, F. L. and Tanner, D. J. 1995. Measurement of expected nucleation precursor species and 3-500 nm diameter particles at Mauna Loa Observatory, Hawaii. J. Atmos. Sci. 52(12), 2242-2257.

Weber, R. J., McMurry, P. H., Mauldin, L., Tanner, D. J., Eisele, F. L. and co-authors. 1998. A study of new particle formation and growth involving biogenic trace gas species measured during ACE 1. J. Geophys. Res. 103(D13), 16385-16396.

Wiedensohler, A., Covert, D. A., Swietlicky, E. S., Aalto, P., and Heintzenberg, J. 1996. Occurrence of an ultrafine particle mode less than $20 \mathrm{~nm}$ in diameter in the marine boundary layer during the Arctic summer. Tellus 48B, 213-222.

Wyslouzil, B. E., Seinfeld, J. H., Flagan, R. C. and Okuyama, K. 1991a. Binary nucleation in acid-water systems. Part 1: methanesulfonic acidwater. J. Chem. Phys. 6(14), 6827-6841.

Wyslouzil, B. E., Seinfeld, J. H., Flagan, R. C. and Okuyama, K. 1991 b. Binary nucleation in acid-water systems. Part 2: sulfuric acid-water and a comparison with methanesulfonic acid-water. J. Chem. Phys. 6(14), 6842-6850.

Yassaa, N., Peeken, I., Zöllner, E., Bluhm, K., Arnold, S. and co-authors. 2008. Evidence for marine production of monoterpenes. Environ. Chem. 5, 391-401, doi:10.1071/EN08047.

Yu, F. 2006. From molecular clusters to nanoparticles: second-generation ion-mediated nucleation model. Atmos. Chem. Phys. 6, 5193-5211.

Yu, F. and Turco, R. P. 2000. Ultrafine aerosol formation via ionmediated nucleation. Geophys. Res. Lett. 6(14), 883-886.

Yu, F. and Turco, R. P. 2001. From molecular clusters to nanoparticles: Role of ambient ionization in tropospheric aerosol formation. $J$. Geophys. Res. 106(D5), 4797-4814.

Zhang, K. M. and Wexler, A. S. 2002. A hypothesis for growth of fresh atmospheric nuclei. J. Geophys. Res. 107(D21), 4577, doi:10.1029/2002JD002180.

Zhang, R., Suh, I., Zhao, J., Zhang, D., Fortner, E. C. and co-authors. 2004. Atmospheric new particle formation enhanced by organic acids. Science 304, 1487-1490. 